\title{
Afrodita y los fenicios en el Egeo*
}

\author{
Miriam VALDÉs GUÍA \\ Universidad Complutense de Madrid \\ mavaldes@ghis.ucm.es
}

Recibido: 17 de junio de 2013

Aceptado: 27 de septiembre de 2013

\section{RESUMEN}

La expansión del culto de Afrodita por Grecia, desde Chipre, fue un fenómeno complejo y prolongado en el tiempo que se dio en época oscura y arcaica. En este proceso, sin duda, jugaron un papel importante los fenicios y las rutas comerciales transitadas por ellos, por chipriotas y griegos desde el s. X a.C. Los fenicios dejaron una impronta reseñable en el culto greco-chipriota de Afrodita, e influyeron, junto con otros factores, en la elaboración mitológica y cultual de algunos rasgos de la diosa, como sin duda, su relación con la guerra.

Palabras clave: Rutas comerciales fenicias en el Egeo. Expansión del culto de Afrodita. Rasgos guerreros.

\section{Aphrodite and Phoenicians in the Aegean}

\begin{abstract}
The expansion of Aphrodite's cult for Greece from Cyprus was a complex phenomenon that lasted during the Dark Age and Archaic Period. The Phoenicians and their trade routes, frequented by Greeks, Phoenicians and Cypriots, played, undoubtedly, an important role in the expansion of the cult since the X Century BC. The Phoenicians left a notable stamp in Greek-Cypriot Aphrodite's worship, and influenced, together with other factors, the mythological and cultic development of some features of the Goddess, since undoubtedly, her relation with the war.
\end{abstract}

Key words: Phoenician trade routes in the Aegean. Expansion of Aphrodite's cult. Warlike features.

Sumario: 1. Introducción. 2. Afrodita y la ruta de los fenicios en el Egeo en época geométrica y arcaica. 2.1 Chipre. 2.2. Citera. 2.3. Creta. 2.4. Argos, Arcadia y Esparta. 2.5. Corinto. 2.6. Atenas. 2.7. Eubea y Beocia. 2.8. Asia Menor. 3. Conclusión.

* Este artículo está realizado en el marco del proyecto del Ministerio de Economía y Competitividad HAR2012-30870: Identidad ciudadana en la polis griega arcaica y clásica y su proyección espacial y cultual. Esta es mi modesta contribución a la memoria de nuestro querido compañero, Fernando López Pardo, a quien tuve el privilegio de tratar, beneficiándome de su amabilidad, de su cortesía y de sus consejos sabios y pacientes. Tuve la suerte de poder conocerlo mejor en nuestra implicación conjunta en desarrollo, todavía incipiente, del Máster en Historia y Ciencias de la Antigüedad, que él, junto con José Pascual y otros colegas, contribuyeron a diseñar y al que dieron su primera forma. Hoy todos sabemos que es un Máster de referencia en Historia Antigua, en el ámbito nacional e internacional. En múltiples ocasiones me alentó, y mostró una gran confianza en mi capacidad para poder gestionarlo a pesar de mi inexperiencia en aquellos momentos. Entre las muchas cosas que tengo que agradecerle y que me es grato recordar, está su participación en el tribunal de mi plaza como "profesor contratado doctor". En aquella ocasión se mostró especialmente interesado en el libro que acababa de publicar de Afrodita en el alto arcaísmo (VALDÉs 2005) y me pidió un ejemplar que le regalé con mucho gusto. Me gustaría aprovechar este interés común, así como las bien sabidas y conocidas relaciones de la diosa griega con los fenicios y sus viajes, para hacer este pequeño homenaje a su memoria que espero hubiera sido de su agrado. 


\section{Introducción}

La idea de que Afrodita viene de Oriente se dio ya entre los propios griegos. Heródoto señalaba un origen fenicio destacando como primer lugar de culto la ciudad siria de Ascalón, de donde pasaría a Citera (Hdt., 1.105.7). En Pausanias la diosa fue en primer lugar venerada por los asirios y después por los de Pafos en Chipre, los fenicios que habitaban Ascalón en Palestina y los de Citera, que lo aprendieron de los fenicios (Paus., 1.14.7). Los lugares más emblemáticos de culto de la diosa son, según Diodoro, el de Érice en Sicilia, Ascalón en Siria, Pafos en Chipre y Citera. ${ }^{1}$

En Homero y en Hesíodo aparece esencialmente vinculada a Chipre y a Citera. En Hesíodo la diosa, después de nacer, se acercó a Citera y de allí se desplazó a Chipre (Hes., Th., $192 \mathrm{ss}$ ). Homero la denomina Kypris pero también Citerea (Od. 8. 286; 18.193) y la Odisea menciona el altar de Pafos de la diosa (Od., 8.362-3). ${ }^{2}$ Tanto Chipre como Citera tienen importantes conexiones, como veremos después, con los fenicios.

En estas páginas vamos a tratar de seguir la "huella" de Afrodita por el Egeo de la mano de los fenicios. Para éstos, detrás de Afrodita, se encuentra la diosa Astarté que identificaban con Afrodita. ${ }^{3}$ Sin duda la diosa griega tiene unas similitudes e incluso, según algunos autores, un origen en la figura de diosas semíticas similares, como la Isthar babilónica o la Astarté fenicia, la Attart venerada en Ugarit a finales del segundo milenio o la Astart conocida en Chipre en el s. IX a.C. ${ }^{4}$ En otro lugar analizábamos el origen de la diosa, llegando a la conclusión de que, sobre un fondo de divinidades femeninas cretenses y micénicas, se "elabora", en el tránsito del segundo al primer milenio, fundamentalmente sobre la diosa chipriota que se remonta al Calcolítico, ${ }^{5}$ pero también a partir de una fuerte influencia oriental que se percibe igualmente en la diosa chipriota del segundo milenio, una deidad "nueva", Afrodita, cuyo nombre es, quizás, de procedencia cretense. ${ }^{6} \mathrm{La}$ diosa, como es bien sabido, no aparece en las tablillas micénicas. Afrodita tiene, por tanto, herencias culturales y religiosas complejas, como puede en efecto reflejarse en su mitología en la que aparece, en una versión, como hija de Zeus y Dione, la deidad de las palomas micénica, o hija de Urano, castrado por Crono, nacida de la espuma de mar, en otra; en ella también se integra, sin duda, la herencia dejada por divinidades femeninas del segundo milenio en Creta y en el Egeo. Esta confluencia de

1 En Diodoro (5.77.5) se habla de los lugares donde Afrodita se detuvo un tiempo: en Érice (en Sicilia), en Citera, en Pafos y en Asia en la zona de Siria. El santuario de Pafos, ya mencionado en Homero (Od., 8.362-3), se relaciona con el de Ascalón de los fenicios (Diod. Sic., 2.4.2; Paus., 1.14.7).

2 Kypris: Ulbrich 2010, 167, n. 5. Altar de Pafos también: Himno homérico, vv. 58-9; RudHardt 1975.

3 Filón de Biblos en Eusebio, Praep. Ev., 1.10.31: Afrodita es Astarté. Burkert 1985, 152-153. Para Afrodita: Pirenne-Delforge 1994. Para Astarté: Bonnet 1996. Para ambas: Pirenne-Delforge - Bonnet 1999. Con una posición más escéptica: Budin 2004.

4 Con influencia también de Anat, entre otras. Ver nota anterior y Dugand 1974, 78; KARAGEORGHIS 1977 , 109; Burkert 1985, 12-13, n. 3. Influencia de las diosas orientales en la divinidad femenina chipriota ya desde el LC IIC: Budin 2002, 152, 199 y ss. (en especial 240-241). Serwint 2002. Cf. Olmo Lete (ed.) 1995,18 y ss.

5 Karageorghis 1977, 103; Karageorghis 1991, 84-85; Maier 1979, 233.

6 Distintas teorías sobre el origen de la diosa: VALdÉs 2005, 16-43. Nombre: VALdÉs 2005, 24-25 (con bibliografía). 
diversas herencias que dio paso al "nacimiento" de Afrodita, la diosa del amor y de la sexualidad, creemos que en ambiente chipriota, se originó como consecuencia de un movimiento migratorio muy importante que se llevó a cabo hacia la isla de Chipre desde el s. XIII a.C. por parte de los aqueos y de habitantes de Creta. Este movimiento se prolongó en los siglos posteriores hasta dar lugar a una comunidad mixta en la que ya en el s. XI a.C. parece que se hablaba el griego, como muestra la inscripción en silábico del nombre heleno de Opheltes. $^{7}$ Desde este entorno, posiblemente, Afrodita "retornó" a Grecia, reasumiendo las herencias precedentes, por ejemplo en Kato Symi, donde el culto tiene continuidad desde el segundo milenio, y en época histórica se veneraba a Afrodita y a Hermes Kedrites, retomando allí, sin duda, la herencia de diosa de brazos alzados, como veremos más adelante.

En otro trabajo señalábamos, con precaución, la posibilidad, a grandes rasgos y de manera "esquemática", de dos momentos de expansión de la diosa chipriota en época oscura. ${ }^{8}$ Un primer momento habría podido coincidir con la primera Edad de Hierro, quizás en torno al tránsito del Submicénico al Protogeométrico; en esas fechas se pone en evidencia la influencia chipriota en el cambio de un estilo cerámico a otro en Atenas y en Lefkandi, localidad que, junto con Creta, nunca rompió los vínculos con Chipre durante la época oscura. Un segundo momento habría sido a partir del "renacimiento" y de la reactivación de los contactos entre Chipre y Oriente con Grecia, a partir de finales del s. X a.C. e inicios del s. IX a.C., momento en el que se desarrolla un nuevo estilo, el Geométrico, en Atenas. En esta segunda "expansión" tienen un protagonismo esencial los fenicios.

En un artículo ya antiguo, Pierre Lévêque ${ }^{9}$ titulaba su estudio del origen y de la expansión del culto de Afrodita, traducido al castellano, así: "Astarté se embarca hacia Citera". En estas páginas pretendemos retomar este título tan emblemático modificando "Astarté" por Afrodita. La diosa griega formada en ambiente chipriota se "expande" a través de las rutas transitadas por fenicios y griegos en el Egeo, jalonadas por varios espacios y lugares significativos para el intercambio no sólo comercial, sino también de ideas, técnicas, imágenes religiosas, etc., y para las relaciones entre chipriotas, griegos y fenicios.

En la "primera expansión" habíamos supuesto hipotéticamente, aunque difícilmente demostrable, dada la falta de restos arqueológicos y de otro tipo de fuentes, la asunción de una Afrodita más vinculada a la fertilidad y a la fecundidad, aunque en ella se den rasgos también del vínculo con el poder y con la realeza, innato en la diosa chipriota. En la "segunda expansión", que se iniciaría desde finales del s. $X$ a.C., fecha en la que los fenicios se instalan en Kommos, al sur de Creta, y sobre todo desde el s. IX a.C., quizás se acentúan los rasgos, ya presentes desde antes, de poder, y específicamente la fisonomía guerrera de la diosa del amor. Precisamente con estos desarrollos se relaciona a la "diosa desnuda" -señora de los animales,

7 DEger-JaLKotzy 1994.

8 VAldÉs 2005, 16 y ss. Idea también de “exportación” del culto en época oscura (de Pafos a Kato Symi en torno al s. X a.C.): Budin 2004, 112.

9 LÉVÊQue 1984. 
presente en el mundo de los guerreros en los lugares de cultos de época geométrica y alto arcaica- estudiada por Nanno Marinatos. ${ }^{10}$

En Oriente, la tradición del vínculo de la diosa del amor y la sexualidad con la guerra era larga, desde la Innana sumeria, pasando por la Isthar babilónica hasta la Astarté fenicia, sin descartar otras figuras como Anat o Asherah. ${ }^{11}$ No puede tampoco precisarse en qué momento ni de qué forma adopta o integra la diosa chipriota/Afrodita estos rasgos guerreros en el primer milenio. En cualquier caso, si, como hemos supuesto, en la expansión de la diosa tuvieron un papel importante los fenicios y las rutas por ellos frecuentadas desde el Geométrico, podría pensarse en la asunción o en la acentuación de estos aspectos en la ya existente Afrodita grecochipriota, a partir del contacto/emulación de divinidades fenicias y especialmente de Astarté, uno de cuyos principales rasgos durante el primer milenio es su relación con la guerra. ${ }^{12}$

Estos rasgos agresivos y guerreros de la diosa del amor en Grecia no tardaron en iniciar, en contexto griego, un "repliegue", si no en el culto (como en Corinto, en Esparta o en Citera), sí en las elaboraciones poéticas como la que nos presenta Homero, para quien a Afrodita no le "están dadas las bélicas empresas" (Il. 5.428430). La diosa no sólo "choca" con Atenea, sino que su relación con la guerra, además, parece que se basa fundamentalmente en el vínculo con Ares.

Lo que vamos a tratar de rastrear en estas páginas son las tradiciones e imágenes mitológicas y de culto de Afrodita vinculadas a los fenicios o fuertemente asociadas a aspectos orientales y fenicios, como la imagen de la "diosa desnuda" o el vínculo con la propia Astarté caracterizada además por el travestismo y la bisexualidad, como diosa urania, de los jardines y de guerra, ${ }^{13}$ en varios lugares de Grecia. Trataremos de ver la posible conexión, si existiera, entre estas elaboraciones y los lugares históricamente frecuentados en Grecia por los fenicios en época geométrica y arcaica, dentro de una ruta o rutas estables desarrolladas en ese periodo que pasaban por Chipre, Creta, Citera, Argos y Esparta, Corinto, Atenas, Eubea, Beocia, las Cícladas, Asia Menor, especialmente en el Dodecaneso, pero también por el norte del Egeo. El contacto con Oriente se retoma en el Ática desde finales del s. X a.C. y se acentúa hacia el 850 a.C., pero no es hasta finales del s. IX a.C. cuando las relaciones se hacen más frecuentes. ${ }^{14}$ En Lefkandi la conexión con Chipre y el mundo oriental nunca se interrumpió. A partir del s. IX a.C. los contactos con los fenicios se hicieron fluidos en todo el Egeo. Sin duda se dieron también acercamientos y

10 Marinatos 2000. Una aproximación a la “diosa desnuda” en relación con Afrodita y Astarté también en BonNet - PirenNe-Delforge 2004.

11 SERWint 2002; Bonnet 2004, 136-137.

12 El texto más antiguo de Astarté en Tiro es el tratado entre Asarhaddon, rey Asiria, y Baal, rey tirio, del 670 a.C.; en él se muestra muy claramente esta proyección guerrera de la diosa: BonNET 1996, 37-38, 63-67 (en la iconografía); KATZENSTEIN 1991, 377. Astarté guerrera en el Antiguo Testamento: BonNet 1996, 56-57 (I Samuel, 31.10). Resaltan su carácter militar: Budin 2002, 245-246 y 249; SERwint 2002, 341; FALsone 1986, 74-76.

13 Para todos esos rasgos ver BonNet 1996. Para Astarté como "diosa desnuda" conocida en el primer milenio por las famosas "placas de Astarté": Bonnet - Pirenne-Delforge 2004, 839-841.

14 Demetriou 1989, 86; Snodgrass 1971, 331-332; Morris 2000, 238 y ss. Coldstream distingue tres etapas: Coldstream 1989; Strom 1992. 
relaciones en periodos posteriores, en época clásica y helenística, que renovaron y reasumieron esa herencia anterior geométrica en contextos históricos diferentes que no trataremos.

Por tanto, nos vamos a centrar, fundamentalmente, en la franja temporal que va desde la época geométrica (finales del Protogeométrico: s. X a.C.) hasta el arcaísmo, sin dejar de considerar tampoco legados o influencias anteriores, así como remodelaciones posteriores. En la mayoría de los casos, por supuesto, no pueden precisarse con certeza ni exactitud las fechas o el origen de determinados rasgos de la diosa en Grecia, o de tradiciones locales asociadas con los fenicios o con lo oriental en general.

Trataremos de adentrarnos en el tema desde dos vertientes: el contacto y/o la presencia estable o relativamente frecuente, por el comercio, de los fenicios en algunos lugares en ese periodo, por un lado, y, por otro, los rasgos fenicios u orientales, o presentados como tales, de Afrodita en los mitos y en el culto en esos emplazamientos, tratando de reflexionar sobre las posibilidades de que se remonten a ese periodo geométrico y arcaico. En muchos casos los rasgos orientales pertenecen ya al patrimonio de la diosa chipriota del segundo milenio sobre la que se forma Afrodita en el tránsito del segundo al primer milenio, lo que no significa que no se reactiven, se enfaticen o se reelaboren en determinados periodos de contactos de Grecia con el mundo oriental, y especialmente en el que estamos considerando. Coincidiendo con esas fechas desde finales del s. X a.C. o desde el s. IX a.C., comienzan a desplegarse en diversos contextos, muchos de ellos sacros, imágenes procedentes o que imitan a otras de Oriente, de diosas desnudas, vinculadas por tanto con esta expansión fenicia, asociadas al poder y a la guerra. Estas figurillas ${ }^{15}$ se encuentran asociadas a diversas diosas del panteón griego, y sin duda, también, a Afrodita.

En cualquier caso, aunque en la Afrodita griega hay una clara impronta de los fenicios, que además contribuyeron a propiciar, a través de sus rutas comerciales, su expansión, el origen de la diosa no se encuentra en Astarté, como bien defiende Budin. ${ }^{16} \mathrm{Su}$ origen se hallaría, más bien, como señalábamos antes, en una formación propia y original de la isla de Chipre, a partir de herencias e influencias tanto minoico-cretenses como levantinas sobre la diosa autóctona chipriota, posiblemente en el tránsito de la Edad de Bronce a la de Hierro.

15 Böhm 1990; Langdon 1984, 171 y ss.; Pirenne-Delforge 2001, 175 y ss. Bonnet - Pirenne-Delforge 2004,850 y ss.

16 Budin 2002; ID. 2004. 


\section{Afrodita y la ruta de los fenicios en el Egeo en época geométrica y arcaica}

\subsection{Chipre}

Comenzamos por el lugar más emblemático del culto de la diosa: Chipre. Allí se constata una presencia estable y asentamientos de fenicios, sobre todo en Amatunte y en Kition, desde finales del s. X a.C., y fundamentalmente en el s. IX a.C. ${ }^{17}$ Desde estos lugares los fenicios frecuentan, en ese periodo, una ruta hasta Eubea, ${ }^{18} \mathrm{y}$ a otras zonas, como veremos más abajo. En Kition se inaugura una colonia fenicia y un templo de Astarté hacia mediados del s. IX a.C. ${ }^{19}$ Del 800 a.C. data una inscripción fenicia en esta localidad dedicada a esta diosa que hace mención de la ofrenda del cabello, refiriéndose quizás al ritual de tonsura fenicio o similar. ${ }^{20}$ Esto influye, sin duda, en el culto de la diosa chipriota, ya en esa época presumiblemente venerada como Afrodita. Imágenes posteriores de Astarté de Kition son idénticas a otras de Afrodita en otros lugares de culto de Afrodita en la isla. ${ }^{21}$

En Pafos, el lugar de culto más representativo en Chipre de la diosa Afrodita, cuyo altar es mencionado por Homero (Od., 8.362-3), el primer templo de la diosa se remonta al 1200 a.C. ${ }^{22}$ Esta localidad tuvo sin duda, también, un contacto asiduo con los fenicios desde época geométrica. Aunque no tenemos constatado el nombre de Astarté hasta el s. IV/III a.C. en una inscripción y dedicación a la diosa ${ }^{23}$ los rasgos orientales del templo y de la deidad de Pafos ${ }^{24}$-llamada Anassa, "Reina", un apelativo muy común para Astarté en Chipre y en Fenicia- ${ }^{25}$ indican unas confluencias importantes con la diosa fenicia. Estas confluencias se dan, sin duda, sobre el fondo de una divinidad que había recibido ya influjo, desde antes, de las diosas orientales del segundo milenio. ${ }^{26}$

En Pafos, especialmente significativa, en cuanto a la imbricación de lo griego con lo oriental/fenicio, se da la doble herencia o tradición del culto de la diosa, vinculada al oriental Kinyras y al Agapenor griego. ${ }^{27}$ Este héroe arcadio de Tegea fue el fundador mítico de Pafos a su retorno de la guerra de Troya y erigió en esta localidad un culto a Afrodita (Paus., 8.5.2), leyenda en la que se ha visto un trasfondo histórico. ${ }^{28}$

17 Lipinski 1995, 24; Karageorghis 1991, 115 y ss.; Reyes 1994, 18-21.

18 Coldstream 1982, 263; ID. 1986; ID. 1989.

19 KarageORGHIS 1977, 109; ID. 1976, 95 y ss.; ID. 1981, 79; ID. 1991, 115-116; ID. 1998a, 105-108; BISI 1986, 341; ID. 1987, 228; VANDENABeEle 1986, 352; Bonnet 1996, 72. También en otra zona de Kition, en Kathari, desde el 850 a.C.: Bonnet 1996, 73; Michaelidou-Nicolau 1987, 331-338; Budin 2004, $114-116$.

20 Bonnet 1996, 71; Ulbrich 2010, 169; Yon 1987, 371, fig. 3.

21 Ulbrich 2010, 170, con n. 17.

22 Maier 1975; ID. 1979; Maier - Karageorghis 1984, 91 y ss. Otros santuarios de la diosa en la isla, como el de Golgos, según Pausanias (8.5.2-3), más antiguo que el de Pafos: Ulbrich 2010.

23 Ulbrich 2010, 169; Bonnet 1996, 76.

24 Bonnet 1996, 77.

25 Diosa de Pafos, Anassa: Masson 1961, 112, n 16; Rudhartd 1975, 113, con n. 12. En relación con Kinyras: MAIER 1979, 232. Para Astarté: LiPINSKi 1995, 139; BonNet 1996, 23, 78.

26 Budin 2002, 199 y ss.

27 Pirenne-Delforge - Bonnet 1999, 261.

28 Karageorghis 1983, 370; ID. 1991, 114; Maier, 1986. Con más cautela: Voyatzis 1985, 158-162. 
Por su parte Kinyras es conocido también como fundador de la ciudad y del santuario de Afrodita ${ }^{29}$ y es presentado aquí como el hijo del héroe epónimo del lugar, Pafos, que había nacido de Pygmalion, figura de claro trasfondo fenicio, vinculado a Astarté y conocido como descendiente de Afrodita. ${ }^{30}$ Kinyras, de origen fenicio o ugarítico, tiene a su cargo el sacerdocio de la diosa, llamada "Reina", a quien se une probablemente en una hierogamia.$^{31}$ El calificativo de "Reina" se da asimismo, como señalábamos antes, a Astarté y a la misma Afrodita en varios lugares de Grecia. El sacerdocio de la diosa de Pafos estaba en manos de la dinastía iniciada por este héroe, la de los Kinyrades. Kinyras de Chipre es, en una versión, el padre de Adonis, nacido del amor incestuoso de éste con su hija Mirra. El héroe funda el santuario de Afka, a las afueras de Biblos, cerca del Líbano, donde los cultos de Afrodita y de Adonis fueron posiblemente precedidos por los de Baalat y su paredro. ${ }^{32}$ En Pafos la diosa se presenta como diosa del amor, reina, celeste, marina y dueña de un oráculo, protagonista de una hierogamia, y posiblemente armada, rasgos todos ellos propios también de Astarté..$^{33}$ Afrodita y Astarté son figuras paralelas que confluyen o pueden influenciarse mutuamente más que derivar una de la otra o viceversa, como señalábamos antes. Esta confluencia no pasó desapercibida a los antiguos, pues ya Heródoto, y luego Pausanias y Luciano, igualaron a Afrodita chipriota con la fenicia Astarté. ${ }^{34}$

En Pafos se practicaba la prostitución sacra vinculada precisamente a la tradición de Kinyras y de sus hijas, condenadas por Afrodita a prostituirse. Bonnet y otros autores suponen la existencia de algún tipo de prostitución sagrada de clara inspiración fenicia,${ }^{35}$ aun cuando esta práctica en el mundo oriental, señalada por Heródoto, ${ }^{36}$ ha sido puesta en duda recientemente. ${ }^{37}$

De forma similar, Amatunte, de fuerte tradición eteochipriota, ${ }^{38}$ había sido fundada, según la leyenda, por Kinyras cuando huyó de Pafos a la llegada de Agapenor. ${ }^{39}$ En esta localidad no se tiene constatado el culto de la diosa pafia hasta el s. VIII a.C., aunque posiblemente se veneraba desde antes a la diosa chipriota, como muestra la presencia de la diosa de los "brazos levantados" en tumbas antiguas de la ciudad. ${ }^{40}$ Los primeros restos del santuario en la acrópolis son del s. VIII a.C. ${ }^{41}$ La influencia

29 Bonnet 1996, 78; Tácito, Historias, 2.3.

30 BonNet 1996, 101; Ateneo, 15.676 a-b.

31 Karageorghis 1977, 116; Rudhartd 1975, 113, con n. 12. Epíteto Anassa (Hsch, s.v.) asociado en Grecia con la hierogamia.

32 Ateneo, 10.456a; Bonnet 1996, 28. Para Baalat ver nota 69.

33 BonNet 1996, 79.

34 Hdt. 1.105-2-4; Paus., 1.14.7; Luciano, Dea Syria 6.

35 Clearco de Soloi, chipriota, ve en esta práctica una expiación de una falta antigua: Clearco, fr. 43a Wehrli=Ateneo, 12.516b. Mencionada en Justino, 18.5.4. Cf. LiPInSKI 1995, 486-489; BonNET 1996, 7980; Rudhardt 1975, 114 y 121; Pirenne-Delforge - Bonnet 1999, 262. Para una tipología: Ribichini 1985. En Grecia matiza la idea de prostitución sacra sin negar su existencia, sobre todo en Corinto: DomínGUEZ MONEDERO 2011; ID. 2010.

36 Hdt., 1.199; BonNET 1996, 28; LIPINSKI 1995, 96.

37 Budin 2004, 102-103; ID. 2008.

38 Hermary $1987,376$.

39 Teopompo, FGrH 115 F 103; Budin 2002, 265 y ss.; Pirenne-Delforge - Bonnet 1999, 263.

40 Budin 2002, 265-265; Ulbrich 2010, 173-174.

41 Hermary 1987, 378. 
fenicia se encuentra muy presente en la ciudad en esas fechas, con mucha cerámica fenicia y menos importaciones griegas, ${ }^{42}$ y se percibe por ejemplo en las imágenes de diosas de terracota iguales a las placas de divinidades levantinas, alguna con los brazos cruzados sosteniendo el pecho, halladas en tumbas. ${ }^{43}$ Las figuras parece que están hechas en Chipre, pero son de inspiración fenicia. Según Budin, en Amatunte, una diosa chipriota se identifica simultáneamente con la Astarté fenicia y con la Afrodita griega. ${ }^{44}$ Existen rasgos claros de la influencia fenicia en la imagen anicónica de culto. ${ }^{45}$ Desde el 850 a.C. la iconografía de la diosa chipriota es fuertemente levantina.$^{46}$ Además, Amatunte es uno de los lugares donde se desarrolla, como en Pafos, la prostitución sacra, de inspiración fenicia según Bonnet. ${ }^{47}$ Otro de los rasgos que recuerda a algunas divinidades femeninas orientales es el carácter andrógino de Afrodita en esta localidad, señalado por el historiador local Peón de Amatunte. ${ }^{48}$

También en Salamina de Chipre Afrodita está asociada con las prostitutas en el culto de Afrodita Parakyptousa, que según Antonino Liberal tiene un origen fenicio. ${ }^{49}$ Además, en esta localidad el culto conjunto de Aglauro y Diomedes, en un ritual vinculado con el sacrificio humano y con la guerra, pudo estar conectado con la diosa en su versión guerrera, dado el vínculo de Aglauro y Diomedes con Afrodita (en Hom., Il., 5, 428-30), y puesto que se celebraba en el mes Afrodisio. ${ }^{50}$ La tradición de una Afrodita armada en Chipre se conoce por una fuente tardía que le atribuye el epíteto encheios ${ }^{51}$ Afrodita "de la lanza", pero puede que sea muy antigua, como mostraría quizás el pasaje de Diomedes y Afrodita en la Ilíada, en el que este atributo guerrero de la diosa está ya en retirada. Precisamente éste es uno de los rasgos más característicos también, no sólo de las diosas levantinas del segundo milenio como Isthar (diosa del amor y de la guerra), sino de la Astarté fenicia ${ }^{52}$ que influenció y contribuyó a "modelar", sin duda, la imagen de la Afrodita guerrera en Grecia y en Chipre desde época geométrica. En Salamina y en otros lugares de Chipre, como en Pafos, así como en otras localidades de Grecia (Eretria y Samos), se encuentra una iconografía del tipo Astarté asociada a carros y caballos u ornamentos de caballos, a veces con leones, lo que remite, según Bonnet, a

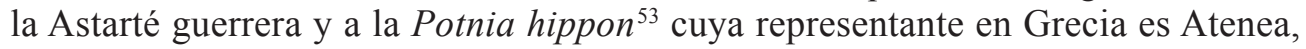

\footnotetext{
42 Hermary 1987, 379-381; LiPINSKi 1995, 141.

43 Hermary 1987, 384-385; Lipinski 1995, 141; Ulbrich 2010, 175. Iconografía en Amatunte de Afrodita como Hathor, que se asocia también a Astarté: UlbRich 2010, 184 (también en Kition: 185-186); BonNET 1996, 84; HeRmary 1987, 385.

44 Budin 2002, 267. Afrodita en Amatunte: Ovidio, Met., 10.220-242; Paus. 9.41.2-5; Tácito, Anales, 3.62; RUDHARDT 1975, 139-142.

45 Budin 2002, 258; en Chipre en general: UlBRICH 2010, 172.

46 Budin 2002, 271; Ulbrich 2010.

47 BonNet 1996, 82.

48 Macrobio, Sat., 3, 8, 1; Peón de Amatunte FGrH 757 F. 1 (Hsch., s.v. Aphroditos); PiRENNE-Delforge 1994, 68.

49 Ovid, Met., 14.689 y ss.; Ant. Lib., Met. 39; Bonnet 1996, 84.

50 Porfirio, Abst., 2, 54; Eusebio, Paep. Ev., 4, 16.2 -155C. VAldÉs 2005a.

51 Hsch., s.v.; Pirenne-Delforge 1994, 361.

52 SERWint 2002, 337 y 341.

53 Bonnet 1996, 66-77; Budin 2002, 252; SERwint 2002, 341-342.
} 
pero a la que no es ajena tampoco Afrodita como muestra su relación con Pegaso en Corinto. De Salamina de Chipre, precisamente, proviene una terracota del s. IV a.C. de una mujer con un escudo apoyado en una mano y un casco en la otra, que podría representar a la diosa. ${ }^{54}$

En Nea Pafos se encontró una estatua de Afrodita con espada de época romana, ${ }^{55}$ pero que tiene su origen en una imagen que se remonta al s. IV a.C. en Epidauro (con copia romana del s. I d.C.) de Afrodita hoplismene o enoplios, "en armas"; a su vez, esta imagen tienen su origen en el xoanon armado de la diosa documentado para Citera o Esparta. ${ }^{56}$ Sea o no la Afrodita encheios chipriota la misma que la hoplismene de Chipre, ${ }^{57}$ representada con espada, o sea un tipo iconográfico distinto, ${ }^{58}$ ambos prototipos muestran que la diosa era conocida en la isla en su vertiente guerrera, como resalta Ulbrich, ${ }^{59}$ quien señala la multiplicidad de funciones y la relación de esta realidad con la tardía integración en Chipre de otras divinidades femeninas griegas, incluyendo a Atenea. También Nancy Serwint ${ }^{60}$ reconoce esta influencia oriental temprana en el carácter armado de la diosa chipriota, aun cuando los testimonios de que disponemos sean tardíos.

Como señalábamos al principio, en la elaboración de esta imagen pudo tener una influencia crucial la diosa fenicia que, según Budin, ${ }^{61}$ se caracteriza sobre todo por su carácter de diosa guerrera, de justicia, protectora de la realeza, similar a la Attart ugarítica del segundo milenio; esta influencia se transmitiría en época geométrica a la diosa chipriota que se ha definido o se está definiendo como Afrodita, sin negar posibles influencias del segundo milenio en este sentido en la diosa chipriota. ${ }^{62} \mathrm{El}$ hecho de que los testimonios que tengamos de la diosa "armada" en Chipre no sean antiguos, no indica que no se conociera ya a Afrodita, sobre todo quizás en Salamina como muestra el pasaje de la Ilíada, en esta vertiente; más bien, podría apuntar a que estos rasgos, más propios de la diosa oriental, no terminaron de ponerse en primer plano en una divinidad con una larga trayectoria, desde el segundo milenio, que enfatiza más otros aspectos de su personalidad, sobre todo la curotrofía y la fertilidad. En cualquier caso, no hay duda de la multiplicidad de funciones que se vinculan a esta diosa poderosa chipriota y que influyó en la tardía entrada de otras divinidades femenina griegas. ${ }^{63}$

54 Budin 2010, fig. 5.1. Del s. IV a.C.: London, British Museum, A 423.

55 DAszewsKi 1976, 220-221, pl., 36. SERwint 2002, 342, fig. 14 (similar en Soloi de Chipre: fig. 15).

56 DASZEWSKI, 1982; ID. 1989.

57 Hadjoannou 1981; HadjIOANNOU - DasZewSKI 1983.

58 DASZEWSKI 1982.

59 Ulbrich 2010, 193; pace Budin 2010.

60 SERWINT 2002, 343.

61 Budin 2002, 242 y ss., especialmente 248-249. No estamos de acuerdo, en todo caso, con esta autora en que los atributos del amor y la fertilidad, característicos de Astarté según BonNeT (1996) desde inicios del primer milenio, no estén en la diosa fenicia en fechas tempranas, en época geométrica, pues aunque no haya textos en este sentido tan tempranos sí hay iconografía abundante que puede ligarse con Astarté y que la presenta en esta línea, como la misma autora reconoce: Budin 2002, 245, 251 y ss.

62 Budin 2002, 202-203.

63 Ulbrich 2010. 


\subsection{Citera}

Aunque Citera es uno de los lugares que con más frecuencia y desde fechas más tempranas se relaciona, en la literatura, con la procedencia "oriental" de Afrodita (Hdt., 1.105.7; Paus., 1.14.7), 1lamada Citerea, epíteto en cualquier caso problemático ${ }^{64}$ y con los fenicios, no se ha encontrado evidencia de la presencia fenicia en la isla durante la época geométrica. La ausencia de restos en este sentido en época oscura puede ser debida a que no se ha descubierto aún el emplazamiento fenicio de la isla, como propone Huxley, ${ }^{65}$ pertenecientes a la etapa geométrica de la que, por otra parte, hay muy pocos hallazgos ${ }^{66}$ No cabe duda de que la isla formaba parte importante de la ruta de los fenicios desde Chipre y Creta hacia el Peloponeso y el Egeo, ${ }^{67}$ y que tuvo, por tanto, un contacto asiduo -si no, un asentamiento- de los fenicios en ese periodo, ${ }^{68}$ quienes contribuyeron quizás a revitalizar un culto anterior. ${ }^{69}$ Jenofonte (Hell., 4.8.7) señala, en el s. IV a.C., que había una bahía llamada Phoinikous en Citera. El propio epónimo de la isla, Kytheros, se decía descendiente de Phoenix, rey de Tiro, y la isla era conocida por su belleza púrpura, ${ }^{70}$ color, por el murex, asociado a Fenicia, "el país de la púrpura". ${ }^{71}$

Afrodita en Citera era conocida como Urania y se presentaba con rasgos guerreros. ${ }^{72}$ Aunque su fundación se asocia a los fenicios, es probable que éstos contribuyan, más bien, a modelar o remodelar un culto anterior, quizás con raíces en la Edad de Bronce, como señalábamos antes. ${ }^{73}$ En cualquier caso, posiblemente, los rasgos de la diosa guerrera en Citera se vieron alentados por la presencia fenicia en la isla, que pudo influir en la elección de Afrodita como divinidad celeste (Urania) y guerrera, a partir de un prototipo que les era familiar, fundamentalmente, en la figura de Astarté, "Reina del Cielo" y con poder militar. No puede negarse, sin embargo, una posible herencia de estos rasgos de la hipotética diosa predecesora en la isla del segundo milenio.

\footnotetext{
64 Hes., Th., 198; Himno homérico, v. 6; Safo, 140a; Boedeker 1974, 19. Problemático: Morgan 1978.

65 HuXLey 1973.

66 Broodbank 1999, 213; Coldstream - Huxley 1973, 34.

67 Di Vita 1998, 175 y 195, con n. 46; Bonnet 1996, 90 y ss.; Markoe 1996, 60.

68 Lipinski 1995, 29-30; Markoe 1998; Pirenne-Delforge - Bonnet 1999, 265.

69 Dugand 1974, 75-76.

70 Phoenix: Bonnet 1996, 90-91. Porphyroussa: Steph. Byz., s.v. kythera; Coldstream - Huxley $1973,26$.

71 Bonnet 1996, 91. El color púrpura es propio también de Afrodita-Blaute: Elderkin 1941a, 382; PIRENNEDelforge 1994, 32.

72 Paus., 3.23.1; Paus., 1.14.7; Hdt., 1.105; Servais-Soyez 1983. El templo de la diosa Urania puede estar, según Coldstream - Huxley $(1973,35)$, en la terraza entre Hagios Kosmas y la capilla de Hagios Georgios en lo alto de la montaña. Allí se encontraron restos arcaicos.

73 West $(1997,56-57)$ señala que Kythereia puede venir de la designación de compañera divina del dios Kothar, dios de la metalurgia del segundo milenio en Levante (LiPINSKi 1995, 108 y ss.; Olmo Lete, ed., 1995, 36) por lo que cree que el nombre de isla Citera se remonta al s. XIV a.C.
} 


\subsection{Creta}

En Creta, uno de los lugares que se ha postulado como lugar originario de Afrodita, ${ }^{74}$ la influencia fenicia es notable en la Edad de Hierro. Allí se instalaron los fenicios directamente desde Levante, y también desde Chipre, ya desde finales del s. X a.C. ${ }^{75}$ En Cnosos se encontró un grafito fenicio del 900 a.C. ${ }^{76}$ lo que indica presencia permanente de orfebres y joyeros fenicios en el s. IX a.C. ${ }^{77}$ especialmente en la segunda mitad, y posiblemente en otros lugares de Grecia también.

El asentamiento fenicio de Kommos, el puerto de Festos, al sur de la isla, se instala en el s. X a.C., siendo frecuentado también por los griegos. ${ }^{78}$ Allí los fenicios erigen un santuario con un altar betílico. Otro punto de contacto de los fenicios en Creta es Falasarna, aunque va a ser ocupada de forma estable más tarde. Desde época arcaica, al menos, está documentado en este lugar (a partir del s. VI a.C.) un probable culto a Astarté en forma de "trono vacío". ${ }^{79}$ Desde allí los fenicios frecuentan la ruta a Citera, al Peloponeso y a Sicilia. ${ }^{80}$ El culto de Afrodita en Sicilia, junto a la tumba de Minos, en Minoa, tiene rasgos que recuerdan el carácter "dual" de Afrodita (Urania, Ctónica), recogido de algún modo en el culto chipriota de Afrodita/Ariadna en su tumba, ${ }^{81}$ pero también en el laberinto cretense, o en Argos, en el culto de Afrodita, Ariadna y Dioniso Cresios. ${ }^{82}$ En Sicilia se venera también a Afrodita en Érice, como Ericina, deidad que varios textos asocian a la diosa oriental, como la Afrodita de Citera o de Chipre. ${ }^{83}$ Detrás de estos cultos de Afrodita sin duda se encuentran influencias cretenses y orientales, vinculadas a la navegación griega y fenicia en rutas establecidas en época geométrica desde Creta (Falasarna, entre otros lugares) por el Egeo y Sicilia, y especialmente frecuentadas por los fenicios.

Entre Kommos, al sur de la isla, y Falasarna se encuentra otro lugar, Loutra, transitado por los fenicios, la antigua Phoenix, que en la mitología, aparece como padre o hermano de Europa y padre de Itanos. ${ }^{84}$

La isla de Creta, además del contacto directo con los fenicios, tiene relaciones asiduas también con Chipre durante toda la época oscura, ${ }^{85}$ donde están asentados los fenicios, como señalábamos arriba, desde finales del s. X a.C.

74 Pugliese Carrateli 1990. Retoma la cuestión cretense: Pirenne-Delforge 2001.

75 Coldstream 1979; ID.1982, 263; ID.1986; Di Vita 1998.

76 Coldstream 1982, 271-272, pl. 27 c-d. Existen copas similares de la segunda mitad del s. IX a.C. en el Cerámico, en Lefkandi, en Chipre y varias en Creta: FaLsone 1987, 181-194. Bisi 1987, 233.

77 Coldstream 1982, 264-266.

78 LiPINSKI 1995, 26; Di ViTA 1998; CSAPO 1991; SHAW 1989.

79 Di ViTA 1998,181 y 183.

80 Di ViTA 1998, 175, 190.

81 Rudhardt 1975, 118-119; Hermary 1982, 164-166; Peón de Amatunte FGrH 757 F 2 = Plut. Thes. 20; FRANKLIN e.p.

82 Laberinto cretense: Diod. Sic., 4.79.3; Pugliese Carratelli 1990, 78-79. Argos: Paus., 2.23.7-8; Musti - Torelli 1986, 289.

83 Diod. Sic. 5.77.5; Domínguez Monedero 2011, 122, con n. 39.

84 Di Vita 1998, 195; Andrewes 1969; Hes., Catálogo de mujeres, 141 M-W.

85 Nicolau 1979, 249; Coldstream 1979; Snodgrass 1971, 328 y 331; Demetriou 1989, 87. 
Sin duda en Creta Afrodita reasume herencias del segundo milenio, en Kato Symi por ejemplo, y de la diosa de los brazos alzados, muy presente en la iconografía chipriota de Afrodita desde inicios del primer milenio. ${ }^{86}$ Incluso es posible que proceda de allí el nombre de la diosa ${ }^{87}$ La divinidad del laberinto, en época histórica la heroína Ariadna, tiene estrecha relación, en todo el mundo egeo y en Chipre, con Afrodita. En Creta, como en muchos lugares de Grecia, entre ellos Chipre, ${ }^{88}$ abundan las figurillas desnudas de inspiración fenicia u oriental, algunas asociadas presumiblemente con Afrodita, como las de Kato Symi ${ }^{89}$ Estas figurillas se hallaron también con profusión en los templos de Prinias y de Gortina. ${ }^{90}$ En Gortina existe un culto o cultos femeninos que se remontan a época geométrica, aunque el templo, tripartito, no se construye hasta el s. VII a.C. ${ }^{91}$ Es posible que aquí, el culto más arcaico -adscrito más tarde unilateralmente a Atenea- y que tiene una fisonomía, en ese periodo, de diosa de la guerra, de la sexualidad y también de "Señora de los animales", pueda ligarse no sólo a Atenea, sino también a otras divinidades como Ártemis o la propia Afrodita. ${ }^{92}$ En cualquier caso, la imagen de Atenea guerrera se vincula o se complementa, en otros contextos también, con Afrodita, como quizás en Corinto, en Atenas, en Tegea o en Lócride. ${ }^{93}$

La propia Afrodita en Creta presenta rasgos que la asocian con la guerra y con el dios Ares, en rituales de iniciación masculino-femenina a la edad adulta. ${ }^{94}$ En Kato Symi la divinidad masculina, luego conocida como Hermes (al menos desde el s. VI a.C.) ${ }^{95}$ incorpora en época geométrica rasgos guerreros; su culto tiene continuidad desde época micénica. ${ }^{96}$ La diosa a la que se rinde culto aquí junto a su paredro es similar a la de Gortina. ${ }^{97}$ Es posible que la divinidad femenina del santuario, quizás ya Afrodita en la Edad de Hierro, adquiera o se relacione con los aspectos guerreros en esas fechas. En el Afrodision situado entre Lato y Olunte, en Creta, era venerada la diosa con Ares en un santuario que se remonta a época geométrica. ${ }^{98}$ Es posible pensar que en estos desarrollos hay una impronta fenicia, aunque la elaboración de estos rasgos, vinculados a la guerra, debe entenderse en el contexto social griego de ese periodo ${ }^{99}$ y se liga, como ha destacado Pirenne-Delforge, a ritos iniciáticos vinculados con la guerra y la caza que acababan en matrimonio. ${ }^{100}$

\footnotetext{
86 Ulbrich 2010, 173.

87 VALDÉs 2005, 24-25, con bibliografía.

88 Figurillas desnudas en Chipre: Karageorghis 1982, 79; Vandenabeele 1986, 352-35.

89 Lebessi 1972, 188a, 189b; Böhm 1990, 167, cat. 55-59; Pirenne-Delforge 2001, 178.

90 Prinias: Carter 1997, 86 y ss.; Gortina: Burkert 1985, 29; BöHm 1990, 162 y ss. Bonnet - PirenNeDelforge 2004, 858 y ss.

91 Perlman 2000.

92 Simon 1970, 13; BRIZE 1997, 134.

93 VALDÉs 2005, passim.

94 Pirenne-Delforge 2001, 172 y ss.; Valdés 2005, 38.

95 Pirenne-Delforge 1994, 5.

96 Byrne 1991, 81-83, 86, 113 y 200.

97 Brize 1997, 134; Pirenne- Delforge 2001, 174-175.

98 Pirenne-Delforge 2001, 173.

99 VALdÉs 2005, passim.

100 Pirenne-Delforge 2001, 174-175.
} 
La herencia cultual y cultural de la Afrodita cretense es compleja, rica y muy antigua; aquí la divinidad o divinidades femeninas del segundo milenio que precedieron a Afrodita contribuyeron a modelar en gran medida la Afrodita griega en Chipre en el tránsito del segundo al primer milenio. A Creta retorna ya la diosa como "Afrodita", y sin duda "navega" también, en parte, de la mano de los fenicios, uno de cuyos aportes en la construcción de la personalidad de la diosa pudo ser, entre otros, enfatizar o poner de relieve su relación con la guerra, aunque luego las elaboraciones en este sentido de la diosa en la isla son complejas y vinculadas a los procesos históricos locales, propiamente griegos, en los que se asumen o reasumen, asimismo, herencias de la o las divinidades femeninas de la isla de épocas anteriores.

\subsection{Argos, Arcadia y Esparta}

Argos forma parte, sin duda, de las rutas comerciales y de navegación de levantinos -sirios- $\mathrm{y}$ fenicios en época geométrica, como testimonia Heródoto (1.1). Los fenicios frecuentaron una ruta de intercambios comerciales con los griegos del Peloponeso y en concreto con Argos, donde tienen una presencia especial los sirios del Norte en el s. VIII a.C. ${ }^{101}$ Los fenicios podrían haber surcado esta ruta en busca de hierro a partir del 900 a.C. desde Creta ${ }^{102}$ y desde Citera, ${ }^{103}$ isla estrechamente vinculada con Argos como testimonia Heródoto (1.82.2). La ruta llegaba o pasaba por territorios del Peloponeso como Esparta o Argos y otras zonas de esta región como Arcadia. ${ }^{104}$

En el Peloponeso existen en efecto tradiciones en las que tiene mucha fuerza una Afrodita guerrera, rasgo de la personalidad de la diosa que pudo enfatizarse o elaborarse en este periodo geométrico, posiblemente motivado, entre otras causas, por los contactos y la influencia fenicia y oriental en esta divinidad femenina, pero elaborado y "comprendido" en el contexto social griego de esa época.

En Argos se desarrolla en este periodo geométrico una aristocracia guerrera, asociada a los caballos pero también a la navegación y al comercio. ${ }^{105}$ En esta localidad, como en Creta, Afrodita está ligada a Ares y Enialio ${ }^{106}$ en un santuario en la ruta de Argos a Mantinea relacionado con la tradición de la expedición contra Tebas. ${ }^{107}$ En Argos mismo la diosa era conocida como Nikephoros (Paus., 2.19.6), "portadora de victoria", epíteto generalmente asociado con Atenea, ${ }^{108}$ y está vinculada a la victoria en la guerra, como en Corinto, sin dejar de interpretarse asimismo como "victoria" matrimonial. En el santuario hay, además, ofrendas de armas desde el s. VII a.C. ${ }^{109}$

\footnotetext{
101 LipinSKi 1995, 29; Aupert 1982; STROM 1992, 58.

102 Snodgrass 1971, 345; Markoe 1998. Ver supra en nota 83 el culto en Argos de Afrodita, Ariadna y Dioniso Cresios. Contactos Creta-Argos en el s. VIII a.C.: Aupert 1982; Courbin 1957.

103 HuXley 1973, 37.

104 PiÉrart - Touchais 1996, 30.

105 COURBIn 1957; Aupert 1982.

106 Pirenne-Delforge 1994, 167-168.

107 Paus., 2.25.1. Billot 1997, 31-32.

108 Goulaki-Voutira et alii 1992.

109 Victoria matrimonial: Pirenne-Delforge 1994, 153. Armas: Marchetti 1993; ID. 1994.
} 
Sin duda, en Argos, esta imagen de Afrodita guerrera se entrelaza de forma conflictiva con los cultos de Atenea guerrera, Diomedes y Ares, vínculo establecido ya en Homero, en el canto quinto, con probable proyección en el culto en Argos y en Chipre. ${ }^{110}$ En la formulación de este mito se percibe una fuerte influencia oriental del mito de Ishtar y Gilgamesh, como ha resaltado Burkert. ${ }^{111}$ Si Atenea guerrera tiene una proyección cultual importante en Argos, en la diosa venerada, desde el geométrico medio, en la acrópolis de Larisa, en conexión con Diomedes, ${ }^{112}$ podemos suponer que también Afrodita guerrera, desvinculada de estos aspectos de la guerra en el discurso mitológico panhelénico de Homero, tendría su proyección cultual en Argos. Muy probablemente esta tradición entra en conflicto, desde época geométrica y en el arcaísmo, con la de Atenea-Diomedes, en momentos en los que se perfilan, se definen y se elaboran los rasgos propios de las divinidades griegas en el discurso mítico en el que Afrodita es "domada" por Zeus. ${ }^{113}$

La Afrodita armada de Argos tiene sin duda una influencia oriental y fenicia en su definición, pero al mismo tiempo se elabora y se perfila en conexión con otras divinidades y con la realidad social argiva, en la que la imagen de la diosa armada queda "relegada" al mundo de la iniciación y de la inversión femeninas, en el ritual de Hybristika, por ejemplo. ${ }^{114}$

En Arcadia encontramos conexiones interesantes que ligan el culto de Afrodita con Chipre y con Oriente, como el de Afrodita Pafia y en plinthioi en el ágora de esta localidad. ${ }^{115}$ Pirenne-Delforgue ${ }^{116}$ asocia a Afrodita con la diosa "del lingote" de Chipre, vinculándola con el trabajo metalúrgico y artesano. Afrodita "Pafia" en Tegea está, además, ligada a la leyenda de Agapenor, ${ }^{117}$ el rey arcadio que emigró a Pafos, donde erigió el templo de Afrodita; desde allí su hija Laodicea envió un peplo a la diosa Atenea Alea en Tegea, estableciendo también el culto de Afrodita "Pafia" en esta ciudad (Paus., 8.53.7), en una leyenda que vincula, por tanto, ambos cultos.

Sin duda a Tegea y a Arcadia en general, llega la influencia fenicia y chipriota en época oscura, a través de $\operatorname{Argos}^{118}$ y de otras localidades como Citera o Esparta. La relación Arcadia-Chipre se manifiesta en el nombre de Opheltes inscrito en silábico chipriota en el s. XI a.C. en esta localidad en dialecto arcado-chipriota, ${ }^{119}$ lo que ha llevado a algunos autores a pensar en la antigüedad del culto de Afrodita "Pafia" en Tegea. ${ }^{120}$ Lo significativo, de nuevo, es el vínculo de ambas diosas en la leyenda, Afrodita Pafia y Atenea Alea, diosa armada del estilo del "Paladio" de Gortina o de

110 Hom., Il., 5.330 y ss.; 364; 846. VALDÉs 2005, 59 y ss.; ID. 2005a.

111 BURKERT 1992, 97.

112 Culto de Atenea: Paus., 2.24.2-5; HäGG 1992, 11; Hall 1995; BiLlot 1997-1998; relación con Diomedes: BURKERT 1992, 97.

113 JACKSON 2010.

114 Graf 1984; Delcourt 1997; Tomlinson 1972, 109; Valdés 2005, 59 y ss.

115 Pafia: Paus., 8.53.7; “en plinthioi”: Paus., 8.48.1; Jost 1985, 147-148; Pirenne-Delforge 1994, 271.

116 Pirenne-Delforge 1994, 269.

117 Paus., 8.5.2-3; GJeRSTAD 1994, 110-112.

118 Piérart-Touchais 1996, 30.

119 Ver nota 8.

120 Karageorghis 1998a 32; Pirenne-Delforge 1994, 329; con cautela: Voyatzis 1985. 
Atenas y en cuyo santuario se han encontrado ofrendas de armas. ${ }^{121}$ Este vínculo evoca la relación de Afrodita, Atenea y Diomedes de Argos. El santuario de Atenea Alea se remonta al final de época micénica en Arcadia, y en él se construyen los primeros santuarios absidales documentados del s. VIII a.C. ${ }^{122}$ Curiosamente tiene elementos procedentes o de inspiración chipriota, como una figurilla femenina desnuda sujetándose el pecho hallada en el templo de la diosa Alea del s. XII a.C. En el santuario se encuentran otras figurillas de "diosas" desnudas, del tipo "Astarté", de época geométrica, ${ }^{123}$ que evidencian los contactos con Chipre y con los fenicios en ese periodo, así como con Creta. ${ }^{124} \mathrm{El}$ culto femenino del santuario podría ser similar al de Gortina, con sus múltiples caras, también de "Señora de los animales" ${ }^{125}$ que se acerca, por tanto, al de Astarté fenicia. En Tegea se encontró una figurilla de diosa sentada de lado sobre un caballo, vínculo que se encuentra también en Pafos ${ }^{126}$ en la diosa Afrodita así como en otros lugares, como Corinto, y en la diosa Astarté.

Aunque no resulta explícito, puede sospecharse un vínculo estrecho entre el antiguo culto de Ares/Enialio en Arcadia y el de Afrodita/Atenea, como ocurre en Creta, con la que comparte mitos como el de Leucipo. ${ }^{127}$ Esta relación se percibe en el culto de Ares Gynaikothoinas en el ágora de Tegea, cerca de Afrodita en plinthioi, vinculado a la heroína Marpersa, similar a la Telesilla argiva, que se asocia a los cultos de Ares y de Atenea. ${ }^{128}$

En Arcadia el vínculo con Chipre y la Afrodita Pafia podría haberse dado desde fechas muy tempranas; esta relación pudo establecerse con las migraciones y los contactos entre el Peloponeso y Chipre desde el final del mundo micénico. No puede dilucidarse cuándo, cómo y por qué se formó o se estableció el culto o los cultos de Afrodita en esta región de Grecia; fue un proceso sin duda complejo y rico, en el que podría rastrearse, de nuevo, la influencia de fenicios y de griegos de otras regiones, del Peloponeso, de Citera, de Creta..., que frecuentan unas rutas por las que se transmiten ideas y rasgos divinos; este sería el caso de la conexión "guerrera" de la diosa, propia de Astarté, que se manifiesta, como en otros lugares de Grecia, específicamente aquí por su relación con Atenea y con Ares/Enialio.

En Esparta, el culto armado de Afrodita, quizás el más famoso, más conocido y de más continuidad y raigambre en épocas posteriores (sin duda motivado por las particulares características de la sociedad espartana), se remontaría también al arcaísmo ${ }^{129}$ y debe entenderse, por tanto, como estamos viendo en estas páginas, en relación con la "expansión" del culto de Afrodita por el Egeo, que adquiere o enfatiza desde fecha

121 VOYATZIS 2002, fig. 15.

122 VOYATZIS 1999.

123 Figurilla del s. XII a.C.: Voyatzis 1985, 158, Pl. XX, 4-7; geométricas: BöHM 1999, 152; OstBy 1994, $134, \mathrm{n}^{\mathrm{o}}$ 2; Voyatzis 2002, 160.

124 Perlman 2000.

125 VoyATZIS 2002, 160.

126 KARAGEORGHIS 1997.

127 Rocchi 1994; Leucipo: Delcourt 1997, 89 y ss.

128 Paus., 8.48.4-5; Paus., 8, 48, 4-5; Paus., 8.47.2; Deinias FGrH 306 F 4; Hdt., 1.66. Polieno, 1.8; Plut., Mor., 232C-C; Rocchi 1994, 71; Graf 1984, 248; Jost 1985, 147-148. Moggi 2005; Valdés 2005, $72-73$. Afrodita en Arcadia: VALDÉs 2005, 69-75.

129 Flemberg 1995, 110; VALDÉs 2005, 44 y ss. 
temprana, probablemente desde época geométrica, rasgos guerreros. Es probable que en esta imagen tuviera un influjo importante el contacto entre griegos y fenicios y las elaboraciones o énfasis que de estas relaciones se derivaron tanto en Chipre como en el Egeo, en el culto de la diosa.

En Esparta Afrodita armada es conocida como Hoplismene (Paus., 3.15.10) y Areia (Paus., 3.17.5), situada en la Acrópolis de la ciudad junto a Atenea Calcíeco, resaltándose, de nuevo, los vínculos entre ambas diosas. ${ }^{130}$ No es descartable un culto antiguo de la diosa con lanza en el antiguo santuario de Amiclas, donde Apolo se destaca por su vínculo con las armas, y en concreto, con la lanza, en época geométrica, ${ }^{131} \mathrm{y}$ en el que la diosa era conocida, al menos en fecha tardía, como Urania. ${ }^{132}$ Nonno (Dion., 43.4-7) alude, por otra parte, a la "lanza (enchos) de bronce" de Afrodita "Amiclea".

Parece, por otro lado, que en la Esparta arcaica se conoció el culto de Afrodita $\mathrm{Ba}$ silis, "Reina", posiblemente en la acrópolis, en el lugar de culto de Atenea Areia. El culto de Basilis es heredado por Tarento, ${ }^{133}$ colonia fundada a finales del s. VIII a.C., y desde donde la influencia de la Afrodita "espartana", en armas, pudo llegar también, junto con otros influjos griegos, a varios lugares de Italia como Gravisca en Etruria o Terracina en el Lacio. ${ }^{134}$

Sin duda Esparta formaba parte de los circuitos que frecuentaban griegos y fenicios y que pasaban, desde época geométrica, por Chipre, Creta, Citera y el Peloponeso. ${ }^{135}$ Esta realidad se percibe de modo directo, por ejemplo, en las ofrendas en el santuario de la diosa Ártemis Ortia, lo que llevó a algún autor, incluso, a postular un origen oriental o fenicio del culto. ${ }^{136}$

En Esparta, como en el resto de los lugares de Grecia, la Afrodita armada y la "influencia oriental" se elaboran de manera propia en relación con desarrollos sociales, culturales y religiosos que vinculan el matrimonio, la guerra y la iniciación y que plantean reflexiones sobre el papel de la mujer en la sociedad espartana. ${ }^{137}$

Aunque la documentación literaria de Afrodita armada no se remonta más allá del s. III a.C., ${ }^{138}$ el culto de la diosa como Areia, epíteto que comparte con Atenea, está documentado en inscripciones arcaicas en la acrópolis de Esparta. ${ }^{139}$ Este culto armado fue heredado por Tarento, que contaba con un culto de Afrodita Basilis, y, quizás, por Tera, fundada a principios del s. VIII a.C., que dispone también de un culto de Afrodita, aunque aquí no se tiene constatada su imagen en armas. Posiblemente en Tera la diosa podría haber estado ligada a Ares Teritas, vinculado a la familia de los

130 Primera mención de Afrodita armada en Esparta en Leónidas de Tarento (mediados del s. III a.C.): Antología Palatina, XVI, 171. Para más fuentes: Flemberg 1991, 29 y ss.; ID. 1995.

131 Paus., 3.19.2; Musti - Torelli 1991, 245; en época geométrica: Byrne 1991, 96 y 164.

132 Flemberg 1991, 50 ss; Pirenne-Delforge 1994, 211 y ss.; IG V 559, lín. 22.

133 Woodward 1928-1929, 250; Osanna 1990; Pirenne Delforgue - Bonnet 1999, 265-266; Tarento: SCHINDLER 1998, 147 y 151.

134 Torelli 1977, fig. 11; Morel 1984, ValdÉs 2005, 54.

135 Di Vita 1998, 175, 195, con n. 46; Bonnet 1996, 90 y ss.; Ps. Scylax 47; Markoe 1998.

136 Ofrendas: DAWKINS 1929, 402; BYRNE 1991, 172; origen oriental: CARTER 1987.

137 VALDÉs 2005, 49-50.

138 Ver nota 131.

139 Woodward 1928-1929, 252-253, nº 8, fig. 7; Musti - Torelli 1991, 231; Pirenne-Delforge 1994, 209. 
Egeidas que se asocian igualmente con Afrodita Basilis de Esparta. ${ }^{140}$ Tera es un lugar frecuentado por los fenicios, en su búsqueda de metales (Hdt. 4.147), junto con Melos y Lemnos en el Egeo. ${ }^{141}$

En definitiva la Afrodita armada del Peloponeso (veremos ahora también el caso corintio) pudo formarse en fecha muy temprana, como supuso Flemberg, ${ }^{142}$ quizás ya en el geométrico, pero su "intromisión" (como se ve bien en el discurso homérico) o su culto, tropiezan -a veces de forma complementaria, a veces con tensiones-, con el de Atenea, Ares y Hera, y aunque termina por encontrar su lugar, sobre todo en Esparta, se asocia fundamentalmente con la imagen, con proyección ritual, del desorden derivado de la implicación femenina en la guerra.

\subsection{Corinto}

En Corinto, la relación con los fenicios es aparentemente más directa y así se manifiesta en varias tradiciones asociadas con el culto de Afrodita, especialmente en la acrocorinto, donde era venerada como Urania y con un xoanon armado (Paus., 2.5.1). Este culto tiene estrechos vínculos con el de Citera (Paus., 1.14.7) de donde según Alcifrón (3.24) procedía. Corinto se encuentra dentro de las rutas frecuentadas por fenicios y griegos desde época geométrica. Allí arribaban sin duda naves fenicias desde ese periodo, ${ }^{143}$ trayendo objetos de procedencia oriental y chipriota. En la ciudad de Corinto existía un mes llamado Phoinikaios y un culto de Atenea Phoinike, ${ }^{144}$ que podría tener que ver con el vínculo entre fenicios y griegos en este lugar. Esta interacción se percibe claramente detrás de los orientalia del santuario de origen geométrico, con restos desde el s. IX a.C., de Hera de Perácora, en el golfo de Corinto, sobre todo a partir del s. VIII a.C. ${ }^{145}$ Allí se encontró una placa del segundo cuarto del s. VII a.C. en la que por un lado se muestra a Afrodita surgiendo de los genitales de Urano, como diosa bisexuada, que alude claramente al mito de su nacimiento en Chipre (Hes., Th., 190 ss), y por el otro, el caballo Pegaso. ${ }^{146}$ Para Payne ${ }^{147}$ el culto de Hera se ve "contaminado" por Afrodita "oriental" en este periodo.

En un estudio sobre el sinecismo de la ciudad, Williams ${ }^{148}$ vinculaba este proceso con Afrodita y atribuía a Afrodita Urania de la acrópolis corintia, que tiene un naidion desde el s. VII a.C., ${ }^{149}$ un origen "oriental". Williams explicaba el vínculo de la diosa

140 VALDÉs 2005, 55-56. Estatua desnuda de Afrodita del s. IV a.C. de tipo de Praxíteles en Tera similar a otra guerrera de Esparta del s. IV a.C.: Dickins 1907-8, 146. Afrodita Urania está presente en Cirene, colonia de Tera: Delivorrias 1984, 56 y 70. Ares Teritas y en relación con Tera los Egeidas: Faustoferri 1996, 214.

Ares Teritas en la ruta a Terapne: Paus., 3.19.7-8.

141 Morris 1992, 136; MALKIn 1994, 92-94; LiPINSKI 1995, 30.

142 Flemberg 1991; ID. 1995; pace Budin 2010.

143 Dunbabin 1948, 66; Morris-Papadopoulos 1998; Markoe 1996.

144 Mes: Meritt 1931, nº 1 y 2; en Corcira y Ambracia: Williams 1978, 54. Atenea: Kardara 1970; VILling 1997, 90; sch., Lycoph, Alex., 658.

145 Novaro-Lefèvre 2000, 65; Morgan 2002, 50; Menadier 2002, 85.

146 PAYNe et alii. 1940, 231, nº 183; Blomberg 1996, 83. ReICHerT-SüDBeCK 2000, 46-47, taf, 1 a.

147 PAYNe et alii. 1940, 232.

148 Williams 1986.

149 Musti - Torelli 1991, 232; Str., 8.6.21 (379); Reichert-SüDBECK 2000, 33. 
con la unificación política por la orientación marítima y comercial de la ciudad, con dos puertos que tienen sin duda focos de artesanos y comerciantes fenicios en época arcaica, ${ }^{150} \mathrm{y}$ el papel de Afrodita como protectora de estas actividades. Más que un "préstamo" fenicio en estos momentos del origen de la polis -en el s. VIII a.C.-, podríamos pensar en el establecimiento o realce de un culto femenino políado, protector de la ciudad y guerrero, pero orientado, al mismo tiempo, a la navegación, ${ }^{151}$ a la protección de determinados sectores (artesanos, prostitutas), y fuertemente sexualizado. Este tipo de culto está presente en el imaginario griego de este periodo geométrico, en el que sin duda ha tenido un impacto el contacto con los fenicios y con su diosa Astarté, hasta el punto de que los griegos presentan, en sus elaboraciones, a su diosa Afrodita como de procedencia oriental además de chipriota, que es quizás más acertado históricamente. La diosa "triunfa", especialmente en su doble faceta como Urania y guerrera, tanto en Corinto como en Citera. Es decir, sin duda el contacto con los fenicios y con Astarté en el Egeo, tuvo un influjo, en época geométrica y alto arcaica, en la elaboración griega de la diosa Afrodita como guerrera y celeste, vinculada, en este caso concreto, además, como en Chipre, a la prostitución sacra, ${ }^{152}$ matizada por algunos autores. ${ }^{153}$

En Corinto se ha encontrado una figurilla desnuda y se han hallado placas "de tipo Astarté" del s. VII a.C. ${ }^{154}$ y el nombre de la diosa fenicia aparece inscrito en un fragmento de cerámica de finales del s. V a.C. ${ }^{155}$ Las relaciones con los fenicios son, por tanto, antiguas, al menos desde el s. IX a.C., y no sólo se perciben en Corinto, sino en otros lugares del Peloponeso, como en Olimpia. ${ }^{156}$ En Corinto Afrodita interactúa también de un modo complejo con los cultos de Atenea y de Hera, en este caso en relación con Medea, como hemos estudiado en otro lugar. ${ }^{157}$ Con Atenea (Hellotia) comparte el vínculo con Pegaso (Pind., Ol., 13.65-6; Pind., Ol., 13.82; Paus., 2.4.1), que aparece también en la placa de Perácora con Afrodita bisexuada y en monedas arcaicas en las que se muestra a la diosa armada por un lado y por el otro a Pegaso. ${ }^{158} \mathrm{Ya}$ hemos señalado la relación, en Chipre por ejemplo, de Afrodita con los caballos, ${ }^{159}$ que se da también en el santuario de Mileto que veremos más abajo, o en Gravisca, ${ }^{160}$ y que es propio también de la diosa Astarté, como señalamos más arriba, que tiene asimismo, en ocasiones, un carácter bisexual. ${ }^{161}$

En definitiva, la diosa elegida para representar el sinecismo corintio en el s. VIII a.C., Afrodita Urania, tiene una imagen, similar a la de Citera, armada y protectora

150 Morgan 1994, 125; Williams 1986, 13 y 21-23; Morris - Papadopoulos 1998, 258.

151 AlONI 1982.

152 Domínguez Monedero 2011, 111 y ss.

153 Pirenne-Delforge 1994, 100 ss; Pirenne-Delforge - Bonnet 1999, 268 y ss.

154 Williams 1986, 12, fig. 1B; PirenNe-Delforge - Bonnet 1999, 269.

155 Williams 1986, 12; Bonnet 1996, 92.

156 BONNET 1996, 91-92.

157 VALDÉs 2005, 76 y ss.

158 BlOMBerg 1996; VALdÉs 2005, 89-90.

159 Karageorghis 1997.

160 Mileto: Budin 2002, 91-92; Graeve 1995. Gravisca: Torelli 1977, 448, n. 95; Sud., Lex. 4653, s.v. Aphrodite.

161 Karageorghis 1997, 197-199. 
de la ciudad. Esta imagen sin duda se formó en época geométrica, en el Egeo y en Chipre, y en ella se ve el influjo fenicio, presente también, de modo paralelo, en la expansión del vínculo entre "la diosa desnuda" y el guerrero.

\subsection{Atenas}

En Atenas se perciben también los contactos con los fenicios a partir del momento en el que se reanuda, de forma más sistemática, la navegación en el Egeo, en el s. IX a.C. Los objetos de procedencia fenicia y oriental pudieron o no venir en barcos levantinos, ${ }^{162}$ pero sin duda el Ática formaba parte de las rutas de navegación frecuentadas por fenicios y griegos. Atenas, en cualquier caso, tiene durante la época oscura contactos con Chipre, especialmente en el s. XI a.C., en el tránsito de la cerámica submicénica a la protogeométrica, ${ }^{163} \mathrm{y}$ reanuda los contactos con esta isla especialmente a partir del s. IX a.C. ${ }^{164}$

Sin duda, como hemos postulado en otro lugar, el culto de Afrodita en Atenas es antiguo y podría remontarse, incluso, al inicio de la época oscura, dados los contactos con Chipre en ese periodo, aunque lógicamente no hay certeza en este asunto. ${ }^{165} \mathrm{La}$ leyenda del origen de su culto se asocia curiosamente al rey Egeo, el padre de Teseo, que lo fundó con el epíteto de "Urania", ${ }^{166}$ pero también a Porfirio de Atmone, cuyo nombre remite a los fenicios (Paus., 1.14.7). La figura de Blaute ("sandalia"), ${ }^{167}$ íntimamente asociada a Afrodita Pandemos, cercana a la acrópolis, se ha asociado con la Baalat Gebal fenicia, asimilada a Afrodita y a Dione y ya venerada desde el s. X a.C. en Biblos. ${ }^{168}$

La topografía de Afrodita en la ciudad de Atenas ha sido objeto de estudios recientes ${ }^{169}$ y se ha resaltado en ellos el vínculo de la diosa con la acrópolis, no sólo en sus

162 Parte de las transacciones comerciales, sin duda, se realizan por parte de los propios griegos, atenienses y especialmente los euboicos que, ya desde el s. IX a.C., tienen frecuentes contactos con Al Mina. Para copas fenicias en Dipylon y en Eleusis del s. IX a.C.: LIPINSKI 1995, 30. Objetos de lujo realizados localmente pero con técnicas aprendidas de los fenicios: Smithson 1968, 78. Coldstream 1977, 55-56; ID. 1982, 264-266. Al Mina: Kearsley 1999; Bisi 1987, 225; Collombier 1987.

163 SNODGRASS 1971, 115-118, 222 y 327; Lemos 2002, 10.

164 Karageorghis 1991, 115; Coldstream 1989, 90-96; ID. 1995, 195; ID. 1996; Lemos-HatCher 1991.

165 VALDÉs 2005, 104 y ss.

166 Pirenne-Delforge 1987, 148 y ss. Urania, epíteto tradicionalmente asociado a los "rasgos" orientales de la diosa, ya desde Heródoto $(1.105,131,199)$; VALDÉs e.p.

167 Aunque no hay documentos que atestigüen su existencia hasta el s. II a.C. ( $I G$ II $^{2} 5183$ ) podría ser un culto antiguo pues se asocia al de Afrodita Pandemos, atribuido a Teseo o a Solón: Paus., 1.22.3; Nicandro de Colofón en Ateneo 13.569d-e; por otra parte Blaute se vincula también tanto con la ninfa Blastas o Baltes, la madre de Epiménides asociado al Ática en el s. VII a.C. y ligado por otras fuentes con Afrodita (OIKONOMIDES 1964, 39 y ss.), como con el héroe Egeo: EldERKIn 1941a. El nombre, reinterpretado como "sandalia" (Poll., 7.87), pudo ser originariamente Blatta ("púrpura") como propone ELDERKIN (1941b, 381) asociado a la diosa. Lido (De Mens., 1.21) lo presenta como el nombre de Afrodita entre los fenicios. El culto de Pandemos/Blaute estaría a los pies del bastión de Nike cerca del heroon de Egeo: BEsCHI 1967-1968. Hesiquio, por su parte, menciona a Blaute como un lugar de Atenas (s.v.). Cf. Pirenne-Delforge 1987, 153 y ss. Sandalia, atributo especial de Afrodita: Pirenne-Delforge 1994, 60-61; Poll., 7.87.

168 Elderkin 1941a; Bonnet 1996, 19 y ss. y 89; Budin 2002, 260; Lipinski 1995, 70- 75. SCANDONE Matthiae 1991, quien señala su cercanía a las diosas Hathor e Isis egipcias.

169 Valdés 2002; RosenzWeig 1999; Pala 2010. 
laderas, como señaló Loraux, ${ }^{170}$ sino quizás sobre la acrópolis misma, como postuló en su día Elderkin, ${ }^{171}$ quien resaltó la posibilidad de que el "Hermes" de mirto de la acrópolis (Paus., 1.27.1) fuera originariamente una representación antigua de Afrodita allí, algo que tendría coherencia con la posibilidad de que las primeras imágenes de la diosa fueran anicónicas o en forma de pilar. ${ }^{172}$ Esta particularidad, junto con la androginia de Afrodita en Atenas, ${ }^{173}$ hace que se perciba una relación estrecha con la diosa de Chipre, pero también con la fenicia Astarté. ${ }^{174}$

Los rasgos de Afrodita en Atenas pudieron tener que ver en origen sobre todo con la diosa chipriota, como diosa del amor, de la fertilidad y de la fecundidad, "soberana". Este vínculo con Chipre está recogido, además, por el culto común en Atenas y en Salamina de Chipre de Aglauro. ${ }^{175}$ En cualquier caso, tampoco está ausente de Atenas la vinculación de la diosa con la guerra, como hemos tratado de argumentar en otro lugar, especialmente quizás en principio en su faceta como "victoriosa", Nike, como en Argos. ${ }^{176}$ Este rasgo aparentemente no perseveró -o no completamentedurante la época clásica, aunque se reavivó en época helenística con la popularidad de Afrodita Hegemone, epíteto que comparte con Ártemis y que está asociado, desde fecha temprana en la polis, al juramento de los kouroi/efebos. ${ }^{177}$

No se puede saber, en la configuración de la Afrodita ateniense, qué viene de Chipre, de los fenicios o de Creta, pues la amalgama es compleja y deriva de influencias y contactos múltiples, pero también de elaboraciones propias o locales y más generales, en el contexto de una red de vínculos con otros griegos del Egeo -como los de Eubea, las Cícladas o Creta, donde se asocia con Ariadna- y del continente.

En la Acrópolis de Atenas, lugar de culto de Atenea guerrera y probablemente de Afrodita, y donde coinciden por tanto, de nuevo, ambas diosas, se encontró una estatuilla de bronce de la "diosa desnuda" del s. VIII a.C. que se suma a otras halladas en el cementerio de Dipylon, ${ }^{178}$ y que ponen de manifiesto el carácter multifacético, por un parte, de la diosa acropolitana principal, Atenea, y quizás, también, el vínculo allí existente de esta diosa con una divinidad femenina ligada a la sexualidad y al poder, como Afrodita.

\footnotetext{
170 LORAUX 1981, 157 y ss.

171 ELDERKIN 1941; VALDÉs 2005, 115.

172 Pirenne-Delforge 1987, 151-152; ID. 1994, 67 y ss.; Langlotz 1954, 26 y ss.; Delivorrias 1984, 10; Osanna 1988-1989, 89; Servais-Soyez 1983, 194; VALDÉs e.p.

173 Filócoro FGrH 328 F 184. En un fragmento de Aristófanes: F 702 Edmonds I., p. 766 y F 313 A Edmonds I, p. 660. Macrobio, Sat., 3.8.3. VAldés e.p. Afrodito, como en Ática desde al s. V a.C. al menos: Hsch., s.v. Aphroditos. Pirenne-Delforge 1994, 68-69. Ferécrates, F 172 A Edmonds I, p. 274; Apolófanes, F 7 Edmonds I, p. 926. Pirenne-Delforge 1987, 151.

174 Settis 1966, 160-161. Afrodita barbada en Chipre: JACOBy, FGrH 757 fr. 1; Pirenne-Delforge 1994, 68. Catull., 68.51. Bisexualidad de Astarté: SEtTis 1966, 166; Bonnet 1996, 83.

175 VALDÉS 2005a.

176 VALDÉs 2005, 105-115.

177 VALDÉs 2005, 126, con blibliografía; BudIN 2010, 92.

178 Böhm 1990, 151 y 156-157, cat. B1 E1; Langdon 1984, 171; Pirenne-Delforge 2001, 176-177.
} 
Cuando en el s. IV a.C. se establezcan colonias fenicias en Atenas ${ }^{179}$ se producirán contactos y "asociaciones" entre Astarté y la Afrodita local, ${ }^{180}$ aunque este culto contaba ya, sin embargo, con una larga trayectoria de vínculo con lo oriental, y unos orígenes asociados a la diosa chipriota y a los propios fenicios, implicados en la navegación en el Egeo desde la época oscura.

No puede negarse la posibilidad de que Afrodita en la Atenas arcaica y geométrica se hubiera vinculado con aspectos asociados a la guerra. Así parece indicarlo la temprana relación de la diosa con Aglauro, Atenea, Hegemone y especialmente con el bastión de Nike. Pero, en cualquier caso, en Atenas, más que en otros lugares del Peloponeso, lo que pesará sobre todo en la personalidad de la diosa, dentro de su multiplicidad y de su complejidad, serán los aspectos asociados con el amor, el matrimonio, la fecundidad y la curotrofía, ${ }^{181}$ sin que pueda dejarse de lado tampoco el vínculo con el poder político, manifestado muy temprano en la diosa con el epíteto Pandemos. Por ello, quizás, puede pensarse en una mayor influencia de Chipre que directamente de los fenicios o también en la existencia más clara y firme desde el inicio de una diosa guerrera bien definida como Atenea, vinculada a la acrópolis.

\subsection{Eubea y Beocia}

Eubea, y específicamente Lefkandi, tuvo un papel importante en la composición de la épica de época oscura ${ }^{182}$ y consecuentemente en la entrada o elaboración de Afrodita en ella -dadas sus conexiones con Chipre, donde pudo desarrollarse una tradición poética paralela en estrecha conexión con la griega-, ${ }^{183}$ además de liderar una koine en la que mantenía el contacto con varios lugares de Grecia como Beocia, el Ática, las Cícladas, la Calcídica, etc. ${ }^{184}$ La primera mención de la diosa (720 a.C.) se da en hexámetros en alfabeto euboico en la copa de Néstor, encontrada en Pitecusa. ${ }^{185}$ Por otra parte, Eubea fue uno de los pocos lugares de Grecia donde no se interrumpieron los contactos asiduos con Chipre y el Próximo Oriente durante toda la época oscura, incluido el s. X a.C. ${ }^{186}$ A mediados del s. IX a.C. las importaciones fenicias se constatan en Lefkandi y en Atenas, ${ }^{187}$ reforzándose los lazos entre Chipre, Levante y Lefkandi durante ese siglo, sobre todo a mediados del mismo. ${ }^{188} \mathrm{El}$ auge de esta localidad comienza a declinar hacia finales del s. IX a.C., coincidiendo, en el último cuarto del mismo siglo, con una época en la que se reaviva probablemente el peligro por la piratería en el Egeo, como ha señalado Snodgrass y demuestra la construcción

179 LIPINSKI 1995, 131.

180 Bonnet 1995, 89; Pirenne-Delforge 1987, 155.

181 Afrodita curótrofa en Atenas: Ateneo, 592a (atribuido a Sófocles o a Homero: Hom. Epigr., 12 Bumeister). Hadzisteliou Price 1978, 128; Pirenne-Delforge 1994, 62.

182 WEST 1988.

183 En este sentido FranKLin (en prensa), destaca la contribución de Chipre a la tradición épica egea y especialmente en las Ciprias y los tres himnos homéricos a Afrodita.

184 LEMOS 2000.

185 KaHIL 1980, 529.

186 РорНАM 1994.

187 LIPINSKI 1995, 30.

188 Popham 1994; Popham et alii. 1980, 357 y ss.; Coldstream 1982. 
de fortificaciones datadas en ese periodo. ${ }^{189}$ En esos momentos se produce un abandono progresivo de Lefkandi y el desarrollo paulatino de Eretria, que disputará con Calcis la fértil llanura lelantina. ${ }^{190} \mathrm{En}$ el s. VIII a.C. la isla de Eubea tiene una intensa actividad comercial y de relaciones con Chipre y Oriente, ${ }^{191}$ en momentos en los que comienza también su colonización. ${ }^{192}$

No conocemos prácticamente nada del culto de Afrodita en este periodo, si existió, en Eubea. ${ }^{193}$ Sin embargo la imagen de una Afrodita con una lanza y escudo hallada en Eretria en un anillo descubierto en una tumba del s. III a.C. - muy similar a otro de Siria- ${ }^{194}$, podría, junto con otros datos que ahora consideraremos, lleva a pensar en la existencia también de una Afrodita armada en esta localidad en fecha temprana. En Eretria y en Calcis, como en otros lugares del mundo griego, se desarrolla una aristocracia guerrera en época geométrica, los temibles Abantes de Homero, caracterizada por su vínculo con los caballos y orientados también a la navegación y al comercio. ${ }^{195}$ La Afrodita con lanza, aunque también documentada en fecha tardía, es un tipo que se desarrolla, como vimos más arriba, en Chipre, con la que Eubea mantiene sistemáticos y continuos contactos en época geométrica. Por otra parte, los Abantes eubeos que menciona Homero en el catálogo de naves, se reconocen como portadores de

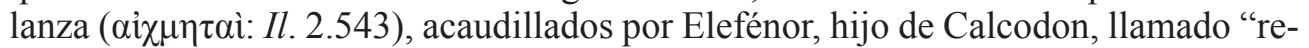

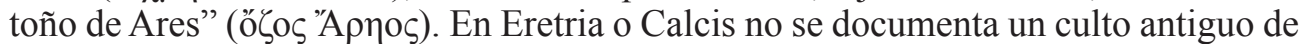
Afrodita, aunque en Eretria podría reconocerse, como veremos ahora y ha supuesto Kahil, en la zona del Palacio III de época geométrica, quizás, junto con Enialio. Sin embargo en Naxos de Sicilia, colonia eubea fundada en el 734 a.C. por Calcis, existe un santuario arcaico atribuido a Afrodita, que tiene material votivo desde el s. VII a.C. En él aparecen, de forma significativa, armas, y entre ellas, también, puntas de lanza. Esto llevó a los que lo excavaron y a otros, a considerar que el culto de la diosa estaba fuertemente vinculado con la guerra. ${ }^{196}$ En un santuario cercano, también arcaico, parece que se veneraba a Enío, la contrapartida femenina de Enialio, por lo que puede suponerse que en esta zona se encontraban juntos, como en muchos lugares de Grecia, Afrodita y Enlialio/Ares. ${ }^{197} \mathrm{La}$ antigüedad de los cultos y sus particularidades pueden hacer factible la hipótesis de que el culto de Afrodita se hubiera inspirado en modelos presentes en el lugar de origen, en Eubea y en Naxos. En Eubea, aunque no está documentada una Afrodita "guerrera" vinculada a la lanza y a Ares en fecha tan temprana (aunque sí, quizás, después, por lo que se ve en el sello), la hipótesis de su

\footnotetext{
189 SNOdgrass 1986; MaZARakis Ainian 1997, 385.

190 KAHIL 1981-1982. Eretria recibe parte de la población de Lefkandi lo que no quiere decir que sea la "Eretria" antigua: ARJonA 2008, 37, 347-348 (con bibiografía). Guerra Lelantina: ARJonA 2008, 399, n. 17541755.

191 Gjerstad 1977; Popham 1994; Ducrey 2005, 564 y ss.

192 POPHAM 1981-1982.

193 ArJona 2008, 188 y ss., 306 y ss., y 485 y ss.

194 Daszewsi 1982, 197, Pl. XLIV, 4; Flemberg 1991, 58; Budin 2010, fig. 5.4; Museum of Fine Arts Boston, 21. 1213.

195 Kearsley 1999. Hippeis: Arist., Ath., 15, 2-3. Abantes: Hom., Il., 2, 536-544. Hes. fr. 204.52-3 West, cf. Hes. fr. 296.

196 Pelagatti 1964, 154-155, fig. 15; Schindler 1998, 208; Guarducci 1985, 15, figs. 5 y 6.

197 Guarducci 1985, 7-34; Pirenne-Delforge 1994, 159, n. 40; Valdés 2005, 39.
} 
existencia en este periodo podría encajar bien en el contexto de un culto geométrico y arcaico de Afrodita guerrera en otros lugares de Grecia; además se explica fácilmente por los contactos asiduos de la isla con los chipriotas -que tienen también una Afrodita de la "lanza"- los fenicios y la costa sirio-palestina.

De hecho en Eretria el "Palacio III" (que se remonta a época geométrica y donde se encuentra, en época posterior, una estatua de Eros, una inscripción de Afrodita y otra posiblemente dedicada a Enialio) ${ }^{198}$ fue interpretado por Kahil, dado el carácter orientalizante de la cerámica geométrica y arcaica, ${ }^{199}$ como un santuario de Afrodita "oriental" o Astarté, ${ }^{200}$ dedicado posiblemente también a Enialio, aunque la falta de datos impone ciertamente cautela. ${ }^{201}$

Karageorghis y Kahil ${ }^{202}$ han destacado los vínculos e intercambios comerciales entre Eretria, Chipre y los fenicios, así como el trasvase de población de Lefkandi hacia Eretria, ciudad que podría remontarse al 800 a.C. No puede extrañar, por tanto, la posibilidad de un culto/imagen de Afrodita con fuertes influencias chipriotas y fenicias en esta zona y, dada la orientación guerrera de la elite, la asunción de Afrodita con estas características en fecha temprana en Eubea que, o bien no pervivió, o, si lo hizo, no ha dejado documentación, aunque la imagen de la diosa con la lanza en el anillo del s. III a.C. es ciertamente sugerente. Por otra parte, al norte del santuario de Apolo se descubrió un espacio sacrificial con ricos hallazgos provenientes de Oriente, con restos desde el s. IX a.C.; ${ }^{203}$ aunque el área se ha vinculado con Ártemis, las similitudes de los hallazgos con los loutrophoroi-hydriai del santuario arcaico, del s. VII a.C., de Nymphe en Atenas, identificada con Afrodita, ${ }^{204}$ pueden mostrar, al menos, la confluencia de estos dos tipos de cultos femeninos en este periodo.

Beocia tiene tradiciones que la ligan a los fenicios, especialmente en la figura de Cadmo de Tebas, como veremos ahora. Esta región se encuentra en época geométrica dentro de la koine cultural liderada por Eubea junto con otros lugares del Egeo. ${ }^{205}$ Precisamente en el contexto de esta koine cultural y en relación con las recitaciones y elaboraciones de la épica en época oscura se debió de ir integrando y asentando Afrodita en ella en sus múltiples conexiones. No es la menor justamente su vínculo con Dione, como hija suya y de Zeus, como aparece en Homero (Il., $5.370 \mathrm{ss}$ ), y que dadas las antiguas conexiones tebanas con Dodona ${ }^{206}$ y la mención de Dione en las tablillas micénicas de Tebas, ${ }^{207}$ pudieron elaborarse en el contacto, dentro de esta koine, de Beocia con Eubea, lugar que, como supuso West, ${ }^{208}$ tuvo un papel relevante en la formación de la épica.

198 KaHIL 1980, 526.

199 KAHIL 1980, 529.

200 KAHIL 1980; ID. 1981-1982, 172.

201 ARJona 2008, 485-486, con bibliografía.

202 Karageorghis - Kahil 1967.

203 Hubert 1998; Ducrey 2005, 564; Mazarakis Ainian 1997, 314.

204 LA RocCa 1972-1973; Dillon 2002, 219.

205 Snodgrass 1971, 228-268; Morris 2000, 196, fig. 6.1; Lemos 2002, 212 y ss.

206 VALDÉs 2005, 94-95, con bibliografía.

207 Aravantinos et alii. 1995.

208 West 1988. 
Entre las leyendas que unen Beocia con el mundo oriental destaca la de Cadmo, el fenicio, que se instala en Tebas (Hdt., 5.58) y se une a Harmonía, la hija de Afrodita y Ares (Hes., Th. 934 y ss.). El mismo Heródoto menciona grammata fenicios (Hdt., 5.58-59), en trípodes quizás de origen chipriota. ${ }^{209}$ Otras tradiciones orientales destacan en Beocia como la de los Cabiros (Hdt., 3.37.9-13), los Dáctilos (Hes., frg., 282 M-W), la invención del trabajo de bronce en Tebas (Hyg., Fab., 274), la de Telquines que emigra de Creta a Chipre y luego a Rodas y Beocia (Paus., 9.19.1).

Es posible que la leyenda de Cadmo "el fenicio" pueda tener un núcleo original de época micénica, momento en el que hay contactos con el mundo oriental, ${ }^{210}$ pero en cualquier caso, como supone Aravantinos, ${ }^{211}$ la leyenda de la llegada de Cadmo desde Fenicia o desde Egipto, se elaboró como tal en época oscura, sin duda por el contacto de Beocia y de la koine euboica con los fenicios. ${ }^{212}$

Afrodita pudo elaborarse y recibir culto en Beocia desde fecha muy temprana, posiblemente alentado por su conexión con Eubea y por los contactos que mantiene la koine euboica con Chipre y el Próximo Oriente. Como en otros lugares ya examinados, en Tebas, Afrodita está asociada a la acrópolis, donde era conocida, entre otros epítetos, como Urania (Paus., 9.16.3). Allí se vincula a la realeza. ${ }^{213}$ La diosa está implicada, además, a través de Harmonía, ${ }^{214}$ con el sinecismo, ${ }^{215}$ como la Afrodita de la acrópolis de Corinto. Se asocia, sin duda, por otra parte, a través de Ares con quien engendra también a Miedo y Terror (Hes., Th. 934 y ss.), con la guerra, aunque tampoco podría descartarse un vínculo más directo con estos aspectos a los que podría aludir su epíteto acropolitano de Apostrophian, "la que rechaza el peligro" ${ }^{216}$ o su relación con el cuerpo de polemarcos tebanos. ${ }^{217}$ Como en otros lugares, Afrodita ${ }^{218 ~ " s e ~}$ encuentra", interactúa o "choca" con Atenea, que recibe en Tebas también influencias orientales a través de su epíteto Onka, asociada igualmente a Cadmo (Paus., 9.12.2), o con la Atenea Itonia, similar a la Ilias o Hellotia de otros lugares. ${ }^{219}$ Además, en Tebas, Afrodita se asocia o se inmiscuye en el ámbito de Deméter, que adquiere rasgos de la Tierra y de reina, conocida igualmente como Erinys y vinculada, como Afrodita, a Ares. ${ }^{220}$

En definitiva, como en todos los lugares que vamos analizando, la Afrodita de Beocia adquiere rasgos múltiples que no se agotan, por supuesto, con los que estamos viendo aquí, y que se elaboran desde la perspectiva de la cultura griega local posi-

\footnotetext{
209 MORRIS 1992, 142 y ss.

210 Porada 1965; Aravantinos 1995; Pirenne-Delforge 1994, 278.

211 Aravantinos 2001, 367-368.

212 SCHACHTER 1985.

213 BRILlante 2001, 274.

214 Conocida también como epíteto de Afrodita en: Call., fr. 654 Pfeiffer; Lucrecio, 4.1248. En el culto en Delfos se encuentra a Afrodita Harma: Plut., Erot., 23.769b; VIAN 1963, 141.

215 Buck 1979, 87; SCHACHTER 1985; VAldés 2005, 96-98.

216 Paus., 9.16.3; Vian 1963, 145; contra: Pirenne-Delforge 1994, 280. Apostrepho tiene este sentido de poner en fuga en la batalla en la Ilíada: Il., 15, 62.

217 SCHACHTER 1982, 167.

218 Para Afrodita en Beocia: Schachter 1981, 36 y ss.; VALdÉs 2005, 92 y ss.

219 BEARZOT 1982.

220 VALDÉs 2005, 94 y 97-98.
} 
blemente desde época oscura, en contacto con Eubea y con otros lugares del Egeo. Esta elaboración se da en una dinámica que construye una imagen de Afrodita griega desde la propia idiosincrasia cultural y social, pero integrando en ese proceso las influencias y los contactos con Chipre y con los fenicios.

\subsection{Asia Menor}

En el Dodecaneso existen múltiples influencias fenicias directamente o a través de Chipre. ${ }^{221}$ Las islas del Dodecaneso cuentan con importaciones chipriotas y fenicias desde el s. X a.C. de forma ininterrumpida. ${ }^{222}$ Posiblemente en esta zona hay comunidades fijas de artesanos fenicios, ${ }^{223}$ tal vez instalados desde Kition en Chipre. ${ }^{224}$ En Rodas, en Camiros y en el santuario de Atenea en Lindos se encuentran estas figurillas de "diosa desnuda", ${ }^{225}$ algunas de procedencia chipriota, ${ }^{226}$ junto con otros objetos variados de procedencia oriental y fenicia, como marfiles, bronces, amuletos, etc., desde el s. VIII a.C. ${ }^{227}$ Conectada con estas influencias chipriotas y orientales se enmarca posiblemente la leyenda de Telquines que comentábamos más arriba, que pasó de Creta a Chipre y luego a Rodas y Beocia. ${ }^{228}$ Existían una o varias rutas frecuentadas por chipriotas, fenicios y griegos, sobre todo euboicos, que pasaban sin duda por Rodas para llegar a Samos, Eubea y el Ática, el golfo sarónico, pero también al norte del Egeo, a la zona de Lemnos, Samotracia y el Pangeo. ${ }^{229}$

En Rodas se tiene constatado un culto de Afrodita reina (Basileias) en fechas posteriores ${ }^{230}$ podría pensarse, quizás, en un origen geométrico o arcaico del mismo, dados los asiduos contactos de esta zona con los fenicios y con Chipre en esos momentos, y la relevancia de Afrodita Anassa en esta isla.

Más al norte, en Mileto, se descubrió hace relativamente poco un templo arcaico de Afrodita en Zeytintepe con terracotas que se remontan al s. VII a.C., ${ }^{231}$ donde se halló una placa de Astarté. ${ }^{232}$ Allí la diosa se asocia también a Pegaso. ${ }^{233}$

Por su parte, Budin ${ }^{234}$ identifica la representación de una diosa armada de época arcaica en el Heraion de Samos como Afrodita, aunque Walter ${ }^{235}$ sugiere que se trata de Atenea. Es significativa la similitud de esta imagen con la que se encuentra representada en un aríbalo de Sición del 725 a.C., en el que se asocian dos diosas, una

221 Coldstream 1982, 264 y 269; ID. 1986, 323; ID. 1998.

222 Bisi 1987, 229-232; ColdSTREAm 1982, 263-264 y 268-269.

223 BONNET 1996, 95.

224 BISI 1987, 234.

225 Laffineur 1978, 33 y ss.; Langdon 1984, 171 y 247; Byrne 1991, 166; BöHm 1990, 156 y 158-160.

226 Pirenne-Delforge 2001, 178; Böhm 1990, 174-176.

227 BONNET 1996, 96.

228 HigBIE 2001, 111.

229 LiPINSKI 1995, 30; MARKoE 1996, 54 y ss.

230 SEG, XLI, 1991, nº 654; ZuSANECK 1994, 419 y ss.

231 Graeve 1995; SenfF 2003; Greaves 2004; ID. 2010, 43, 132 y 148.

232 Graeve 1995, fig. 4.

233 HeinZ - SenfF 1995, 223; Budin 2002, 91-92; Graeve 1995.

234 Budin 2002, 28, n. 50.

235 Walter 1959, 58. 
armada con lanza y escudo, y otra, coronada de un polos, con un objeto redondo, una manzana o una granada. ${ }^{236}$ Afrodita era venerada en Samos con Hermes en los confines del santuario de Hera. ${ }^{237}$ Allí precisamente se encontraron figurillas de la diosa desnuda en el Heraion de Samos ${ }^{238}$ y otros objetos de carácter orientalizante, ${ }^{239}$ como ornamentos para caballo en bronce similares a los hallados en Salamina de Chipre y en Eretria, en una iconografía que evoca la de la diosa Astarté guerrera, señora de los caballos y guía del carro, especialmente en Egipto. ${ }^{240}$

En la costa de Asia Menor existe una tradición de Afrodita armada en época helenística $^{241}$ que aunque, sin duda, relacionada con los desarrollos de ese periodo, pudo rescatar una imagen anterior de la diosa como guerrera. En la zona se conoce a Afrodita, probablemente desde tiempos antiguos, en su versión de curótrofa, como Apaturia, ${ }^{242}$ epíteto que en otras ocasiones se le da a Atenea, y que muestra tanto posibles contactos con Chipre, como comunicación, en época oscura y dentro de esta koine euboica, con Eubea y el Ática, en el contexto de la construcción y definición de "lo jonio".

En Asia Menor, como en otros lugares, Afrodita entra en contacto/“competición" con Hera (en Samos) o con Atenea (en Rodas), como puede mostrar también, por otra parte, el desarrollo mítico del juicio de Paris en esta zona entre las tres diosas, conocido ya en las fuentes más arcaicas. ${ }^{243}$ Sin duda también se vincula con la Madre de los dioses, Cibeles, de quien adopta ciertos rasgos como muestra ya el temprano himno homérico a Afrodita, en el que se pone de manifiesto el carácter en cierto modo "peligroso" de la diosa. ${ }^{244}$

Existen en estas zonas de la costa de Asia Menor y de las islas otros cultos de Afrodita que tienen su origen en el arcaísmo o en época geométrica, como el de Caria ${ }^{245}$ o el famoso de Cnidos, donde era venerada como Euploia, Doritis y Akraia (Paus., 1.1.3). Aquí, como en el resto de Grecia, la construcción de Afrodita se realiza localmente pero desde influencias múltiples en las que fenicios y chipriotas juegan un papel importante.

\section{Conclusión}

Sin duda los lugares tratados no agotan los espacios en los que explorar los rasgos de Afrodita que pudieron formarse en ambiente griego pero en contacto y con influen-

\footnotetext{
236 Johansen 1923, fig. XX.1. Pirenne-Delforge 1994, 135-136. Reichert-Südbeck 2000, 47.

237 Budin 2002, 90.

238 BRIZE 1997.

239 Bisi 1987, 226-227.

240 Bonnet 1996, 66-67 y 77; Budin 2002, 254. En Egipto: Léclant 1991, 13.

241 Budin 2010,83.

242 Cassola 1957, 227; Greaves 2010, 220.

243 Carr Soles 1976, 134; KahIL 1991, 363-364.

244 NÄSSTRÖM 1998.

245 Brody 2001. En Cos se conoce una inscripción dedicada a Afrodita/Astarté del s. IV a.C. como patrona de navegantes: BonNET 1996, 88.
} 
cias fenicias y chipriotas en época geométrica y arcaica; este es un periodo esencial de gestación y de elaboración de la fisonomía de las divinidades del panteón helénico y en el que se da, sobre todo desde el s. IX a.C., un fluido intercambio de ideas y de influencias, construidas, eso sí, localmente y en contacto de unas comunidades griegas con otras, con características propias aunque se presenten con una "aura oriental". En estas páginas hemos tratado de imaginar dónde y en qué periodo se formaron o enfatizaron algunos de los rasgos de la diosa que tradicionalmente se han conectado con el mundo oriental, especialmente, entre otros, el de divinidad guerrera, pudiendo constatarse, efectivamente, un ambiente de relaciones y de contactos múltiples con los fenicios en una red amplia de rutas comerciales transitadas por ellos y por los griegos, que se constituye en la vía privilegiada de transmisión de ideas, creencias y rasgos divinos, aun cuando se elaboren luego internamente de acuerdo a las necesidades y desarrollos locales.

En estas elaboraciones adquieren relevancia determinadas características, en el contexto de creación de elites guerreras en ambiente griego, como, entre otros, los de la diosa oriental que compagina el amor con el poder guerrero, que se vincula también, en varios lugares, a ritos de iniciación de adolescentes en Grecia. Afrodita integra estos aspectos del poder guerrero pero de forma conflictiva a nivel mítico y cultual, entrando en competición con otras diosas, como Atenea, y asociándose a la imagen contradictoria de la mujer armada que se da en un contexto ritual de reversión del orden establecido en Grecia.

En estos procesos de asimilación y elaboración de rasgos orientales, la navegación de los fenicios por el Egeo y los contactos e intercambios entre griegos, fenicios y chipriotas en época geométrica y arcaica, tuvieron sin duda un papel esencial, de modo que, parafraseando el título del artículo de Pierre Lévêque ${ }^{246}$ con el que comenzábamos este artículo, podríamos terminar diciendo que "Afrodita se embarca hacia Grecia" en naves fenicias.

\section{Bibliografía}

Aloni, A. (1982): "Osservazzioni sul rapporto tra schiavitú, commercio e prostituzione sacra nel mondo arcaico", Index 11, 257-263.

Andrewes, P. B. S. (1969): “The Myth of Europa and Minos", $G \& R$ 16, 60-66.

Aravantinos, V.

(1995): "Old and New Evidence for the Palatial Society of Mycenaean Thebes: an Outline", [en] R. Laffineur - W. D. Niemeier (eds.), Politeia. Society and State in the Aegean Bronze Age (Heidelberg 1994), (=Aegaeum 12), 613-621.

(2001): "Influenze orientali a Tebe? La documentazione archeologica ed epigrafica micenea”, [en] Ribichini et alii (eds.), 2001, 363-372.

Aravantinos, V. ET ALII (1995): "Sui nuovi testi del palazzo di Cadmo a Tebe", RAL, s.9, v.6, 809-845.

246 LÉVÊQUE 1984. 
ArJona, M. (2008): Cultos y santuarios de los eubeos: periodos geométrico y arcaico, Tesis doctoral, Universidad de Zaragoza.

Aupert, P. (2982): “Argos aux VIII-VII siècles: Bourgade ou métropole?”, ASAA 44, 21-31.

Bearzot, C. (1982): “Atena Itonia, Atena Tritonia e Atena Iliaca”, CISA 8, 1982, 43-60.

Beschi, L. (1967-1968): “Contributi di topografia ateniese”, ASAA 29-30, 511-536.

BiLlot, M. F.

(1997): "Recherches archéologiques récentes à l'Héraion d'Argos”, [en] Genière (ed.), 1997, 11-81.

(1997-1998):“Sanctuaires et cultes d'Athéna à Argos”, OAth 22-23, 7-52.

Bisi, A. M.

(1986): "Le rôle de Chypre dans la civilisation phénicienne d'Occident: état de la question et éssai de synthèse", [en] Karageorghis (ed.), 1986, 241-359.

(1987): “Ateliers phéniciens dans le monde égéen”, [en] Lipinski (ed.), 1987, 225-237.

Blomberg, P. (1996): On Corinthian Iconography. The Bridle Winged Horse and the Helmeted Female Head in the Sixth Century BC, Uppsala.

BoedeKer, D. D. (1974): Aphrodite Entry into Greek Epic, Leiden.

BöHм, S. (1990): Die “nackte Göttin”. Zur Ikonographie und Deutung unbekleideter weiblicher Figuren in der frühgriechischen Kunst, Mainz.

BONNET, C.

(1996): Astarté. Dossier documentaire et perspectives historiques (=Contributi alla Storia della Religione Fenicio-Punica II), Roma.

(2004): "Le roi et la déesse. À propos de la dédicace grecque à Ptolomée et Aphrodite de la grotte de Wasta, près de Tyr", SEL 21, 125-140.

Bonnet, C. - Pirenne-Delforge, V. (2004): “Cet obscur objet du désir. La nudité féminine entre Orient et Grèce", MEFRA 116/2, 827-870.

Brillante, C. (2001): "Eroi orientali nelle genealogie greche", [en] Ribichini et alii (eds.), 2001, 255-279.

Brize, Ph. (1997): “Offrandes de l'époque géometrique et archaïque á l'Héraion de Samos”, [en] Genière (ed.), 1997, 123-139.

Brody, L. R. (2001): "The Cult of Aphrodite at Aphrodisias in Caria”, Kernos 14, 93-109.

Broodbank, C. (1999): "Kythera Survey: Preliminary Report on the 1998 Sesion”, ABSA 94, 191-214.

Buck, R. J. (1979): A History of Boeotia, Edmonton, Alberta.

Budin, S. L.

(2002): The Origin of Aphrodite, (CDL Press Bethesda), Maryland.

(2004): “A Reconsideration of Aphrodite-Ashtart Syncretism, Numen 51, 95-145.

(2008): The Myth of Sacred Prostitution in Antiquity, Cambridge.

(2010): “Aphrodite Enoplion”, [en] Smith - Pickup (eds.), 2010, 79-112.

BURKERT, W.

(1985 [1977]): Greek Religion. Archaic and Classical, Oxford.

(1992): The Orientalizing Revolution. Near Eastern Influence on Greek Culture in the Early Archaic Age, Cambridge-London.

Byrne, M. (1991): The Greek Geometric Warrior Figurine. Interpretation and Origin, Louvain-La-Neuve. 
Carr Soles, M. E. (1976): Aphrodite at Corinth: A Study of the Sculptural Types, Ann ArborMichigan-London.

CARTer, J. B.

(1987): “The Masks of Ortheia", AJA 91/3, 355-383.

(1997): “Thiasos and Marzeah", [en] S. Langdon (ed.), New Light on Dark Age, Columbia, 72-112.

Cassola, F. (1957): La Ionia nel mondo Miceneo, Napoli.

Coldstream, J.

(1979): "Some Cypriote Traits in Cretan Pottery, c. 950-700 B.C.", [en] Karageorghis (ed.), 1979, 256-263.

(1982): “Greeks and Phoenicians in the Aegean", [en] H. G. Niemeyer (ed.), Phönizier im Western (Symposium über die phönizische Expansion im westlichen Mittelmeerraum, Köln, 24-27 April 1979), Mainz-Rhein, 261-275.

(1986): "Kition and Amathus: Some Reflections on their Westward Links During the Early Iron Age", [en] Karageorghis (ed.), 1986, 325-326.

(1989): "Early Greek Visitors to Cyprus and the Eastern Mediterranean", [en] V. TattonBrown (ed.), Cyprus and the East Mediterranean in the Early Iron Age, London, 90-96. (1995): “Amathus Tomb NW 194: the Greek Pottery Imports", RDAC, 187-198.

(1996): "Knossos and Lefkandi: The Attic Connections", [en] Minotaur and Centaur. Studies in the Archaeology of Crete and Euboea Presented to Mervyn Popham (=BAR International Series 638), Oxford, 133-145.

Coldstream, J. - Huxley, G. L. (EDs.), (1973): Kythera (Excavations and studies conducted by the University of Pennsylvania Museum and the British school at Athens), London.

Collombier, A.-M. (1987): "Céramique grecque et échanges en Méditerranée orientale: chipre et la côte syro-phénicienne (fin VIIIe - fin IVe siècles av. J.-C.)", [en] Lipinski (ed.), 1987, 239-248.

Courbin, P. (1957): “Une tombe géométrique d'Argos”, $B C H$ 81, 353-354.

Csapo, E. (1991): “An International Community of Traders in Late 8th-7th c. B.C. Kommos in Southern Crete", ZPE 88, 211-216.

Daszewski, W. A.

(1976): “Les fouilles polonaises à Nea Paphos 1972-1975. Rapport Préliminaire”, $R D A C$, $185-225$.

(1982): “Aphrodite Hoplismene from Nea Paphos", RDAC, 195-201.

(1989): "Aphrodite from Paphos and from Egypt", [en] Cyprus and the East Mediterranean in the Iron Age, (Proceeding of the seventh british Museum Classical Colloquium, April, 1988), London, 122-131.

Dawkins, R. M. (ED.), (1929): The Sanctuary of Artemis Orthia at Sparta (=JHS suppl., 5), London.

Deger-Jalkotzy, S. (1994): "The Post-palatial Period of Greece: An Aegean Prelude to the 11 th Century B.C. in Cyprus", [en] V. Karageorghis (ed.), Cyprus in the 11th Century B.C. (Proceeding of the International Symposium Cyprus in the 11th Century B.C. organized by the Archaeological Research Unit of the University of Cyprus and the Anastasios $G$. Leventis Foudation, Nicosia, 30-31 October, 1993), Nicosia, 11-30.

Delcourt, M. (1997 [1983]): "La pratica rituale del travestismo", [en] C. Calame (ed.), L'amore in Grecia, Roma-Bari, 87-101. 
Delivorrias, A. (1984): “Aphrodite”, LIMC, Zürich-München, vol. II.1, 2-151.

Demetriou, A. (1989): Cypro-Aegean Relations in the Early Iron Age, Göteborg.

Di VitA, A. (1998): "I Fenici a Creta. Kommos, i "troni di Astarté" a Phalasarna e la "rotta delle isole"", ASAA 70-71, nuova serie 54-55, 175-203.

Dickins, G. (1907-1908): "Excavations at Sparta, 1908”, ABSA 14, 142-146.

Dillon, M. (2002): Girls and Women in Classical Greek Religion, London-New York.

Domínguez Monedero, A. J.

(2010): "La prostitución sagrada en el Mediterráneo antiguo, entre la marginalidad y la integración”, [en] A. Domínguez Arranz (ed.), Mujeres en la Antigüedad Clásica. Género, poder y conflicto, Madrid, 77-101.

(2011): "Las esclavas sagradas de Afrodita", ARYS 4, 111-140.

DuCREY, P. (2005): “Quarante années de fouilles suisses à Érétrie (Grèce), 1964-2004: bilan et perspectives", CRAI 149/2, 553-578.

Dugand, J.-E. (1974): “Aphrodite-Astarté (de l'étymologie du nom d'Aphrodite)”, [en] Hommage à P. Fargues, Paris, 73-98.

Dunbabin, T. J. (1948): “The Early History of Corinth”, JHS 68, 59-69.

ELDERKIN, G. W.

(1941): "The Cults of the Erechtheion", Hesperia 10, 113-124.

(1941a): "The Hero on a Sandal", Hesperia 10, 381-387.

FALSONE, G.

(1987): "La coupe phénicienne de Fortetsa, Crète: une reconsideration", [en] Lipinski (ed.), 1987, 181-194.

(1986): “Anath or Astarte? A Phoenician Bronze Statuette of the Smitting Goddess", [en] C. Bonnet et alii (eds.), Studia Phoenicia IV. Religio Phoenicia, Namur, 53-76.

Faustoferri, A. (1996): Il trono di Amyklai e Sparta. Batykles al servizio del potere, Napoli.

FLEMBERG, J.

(1991): Venus Armata. Studien zur bewaffneten Aphrodite in der griechisch-römischen Kunst, Stockholm.

(1995): "The Transformations of the Armed Aphrodite", [en] B. Berggreen - N. Marinatos (eds.), Greece and Gender, Bergen, 109-122.

Franklin, J. C. (e.p.): “Cyprus, Greek Epic, and Kypriaka”, [en] Y. Maurey et alii (eds.), Yuval. Studies of the Jewish Music Research Centre. Vol.8: Sounds from the Past: Music in the Ancient Near East and Mediterranean Worlds [Jerusalem, 2010].

GeniÈre J. DE LA (ED.), (1997): Héra, Images, espaces, cultes. Actes du Colloque International du Centre de Recherches Archéologiques de l'Université de Lille IIII et de l'Association P.R.A.C., Lille, 29-30 novembre 1993, Naples.

GJERSTAD, E.

(1944): "The Colonization of Cyprus in Greek Legend", OpArch 3, 107-123.

(1977): Greek Geometric and Archaic Pottery Found in Cyprus (=Acta Instituti Atheniensis Regni Sueciae, XXVI), Athens.

Goulaki-Voutira, A. ET ALII (1992): "Nike”, LIMC, Zürich-München, vol. VI.1, 850-904.

Graeve, V. (1995): “Milet 1992-1993”, AA 110, 195-203.

GrAF, F. (1984): “Women, War and Warlike Divinities”, ZPE 55, 245-254. 
Greaves, A. M.

(2004): "The Cult of Aphrodite in Miletos and its Colonies", AS 54, 27-33.

(2010): The Land of Ionia. Society and Economy in the Archaic Period, Oxford.

GuArducci, M. (1985): "Una nuova dea a Naxos in Sicilia e gli antichi legami fra la Naxos siceliota e l'omonima isola delle Cicladi”, MEFRA 97, 7-34.

HadjIOAnnou, K. (1981): “Aphrodite in Arms”, RDAC, 184-186.

Hadionnnou, K. - Daszewski, W. (1983): “The Egcheios Afrodite again”, RDAC, 281-282.

Hadzisteliou Price, Th. (1978): Kourotrophos, Leiden.

HäGG, R. (1992): “Geometric Sanctuaries in the Argolid”, [en] M. Piérart (ed.), Polydipsion Argos. Argos de la fin des palais mycéniens à la constitution de l'État classique, Fribourg (Suisse) 7-9 mai 1987 (=BCH suppl. 22), Paris, 9-36.

HägG, R. (ED.), (2002): Peloponnesian Sanctuaries and Cults (Proceedings of the Ninth International Symposium at the Swedish Institute at Athens, 11-13 June 1994), Stockholm.

Hall, J. M. (1995): "How Argive was the "Argive" Heraion? The Political and Cultic Geography of the Argive Plain, 900-400 B.C.", AJA 99, 577-613.

Heinz, M. - SenfF, R. (1995): “Grabung auf dem Zeytintepe”, AA 1995, 220-224.

HERMARY, A.

(1982): "Divinités chypriotes, I", RDAC, 164-173.

(1987): “Amathonte de Chipre et les phéniciens”, [en] Lipinski (ed.), 1987, 375-388.

Higbie, C. (2001): "Homeric Athena in the chronicle of Lindos", [en] S. Deacy - A. Villing (eds.), Athena in the Classical World, Leiden-Boston-Köln, 105-125.

Hubert, S. (1998): "Une aire sacrificielle proche du Sanctuaire d'Apollon Daphnéphoros à Érétrie. Approches d'un rituel archaïque", [en] R. Hägg (ed.), Ancient Greek Cult Practice from the Archaeological Evidence (Proceedings of the Fourth International Seminar on Ancient Greek Cult, organized by the Swedish Institute at Athens, 22-24 October 1993), Stockholm, 141-155.

Huxley, G. L. (1973): "The History and Topography of Ancient Kythera”, [en] Coldstream Huxley (eds.), 1973, 30-40.

JACKSON, K. (2010): "Father-Daughter Dynamics in the Iliad: the Role of Aphrodite in Defining Zeus' Regime”, [en] Smith - Pickup (eds.), 2010, 151-163.

Johansen, K. F. (1923): Les vases sicyoniens, Paris.

Jost, M (1985): Sanctuaires et cultes d'Arcadie, Paris.

KAHIL, L.

(1980): “Contribution à l'étude de l'Éretrie géométrique”, [en] STELE. Tomos eis mnemen Nikolaou Kontoleontos, Athena, 525-531.

(1981-1982): "Érétrie à l'époque géometrique", [en] Grecia, Italia e Sicilia nell'VIII e VII secolo a.C. (congreso Atene, ottobre, 1979), ASAA 43-44, 165-173.

(1991): "Concours de beauté en Grèce et au proche-orient", [en] Ho hellenismos sten anatole, International Meeting of History and Archaeology, Delphi 6-9 November 1986, Athens, 361-372.

KARAGEORGHIS, J.

(1977): La grande déese de Chypre et son culte à travers l'iconographie, de l'époque néolitique au VIème s. $a$. C., Lyon.

(1976): Kition. Mycenaean and Phoenician Discoveries in Cyprus, London. 
(1981): "De l'adaptation et de la transformation de la mythologie grecque à Chypre durant les périodes archaïque et classique”, [en] L. Kahil - C. Augé (eds.), Mythologie grécoromaine. Mythologies périphériques. Études d'iconographie, Paris, 77-87.

(1983): Palaepaphos-Skales. An Iron Age cementery in Cyprus, Konstanz.

(1991): Les Anciens chypriotes. Entre Orient et Occident, Paris.

(1997): “An Enthroned Astarte on Horseback (?)”, RDAC, 195-203.

(1998): “Astarte at Kition”, [en] R. Rolle - K. Schmidt - R. F. Docter (eds.), Archäologische Studien in Kontaktzonen der antiken Welt, Göttingen, 105-108.

(1998a): Greek Gods and Heroes in Ancient Cyprus, Athens.

KARAGEORGHIS, V. (ED.)

(1979): The Relations between Cyprus and Crete, ca. 2000-500 B.C. (Acts of the International Archaeological Symposium. Nicosia 1978), Nicosia.

(1986): Cyprus between the Orient and the Occident (Acts of the International Archaeological Symposium, septembre 1985), Nicosia.

Karageorghis, V. - Kahil, L. (1967): “Témoignages eubéens à Chypre et chypriotes à Eretrie", $A K 19,133-135$.

Kardara, CH. (1970): “Athena Phoinike”, $A A A$ 3, 94-97.

Katzenstein, H. J. (1991): "Some Reflections on the Phoenician Deities Mentioned in the Treaty Between Esarhaddon King of Assyria and Baal King of Tyre", [en] E. Acquaro et alii. (eds.), Atti del II Congresso Internazionale di Studi Fenici e Punici (Roma, 9-14 Novembre 1987), Roma, vol. I, 373-377.

Kearsley, A. (1999): "Greek Overseas in the 8th Century B.C.: Euboeans, Al Mina and Assyrian Imperialism”, [en] G. R. Tsetskhladze (ed.), Ancient Greeks West and East, LeidenBoston-Köln, 109-134.

LA RoccA, E. (1972-73): “Una testa feminile nel museo nuovo dei conservatori e l'Afrodite Louvre-Napoli”, ASAA 34-35, 419-450.

LAFFInEuR, R. (1978): L'orfèvrerie rhodienne orientalisante, Paris.

Langdon, S. (1984): Art, Religion, and Society in the Greek Geometric Period: Bronze Antrhropomorphic Votive Figurines, University of Indiana, $\mathrm{Ph}$. D. Thesis.

LANGLotz, E. (1954): Aphrodite in den Gärten, Heidelberg.

Lebessi, A. (1972): “Hieron Hermou kai Aphrodite eis Symnes Kretes", Praktika, 193-203.

LÉClant, J. (1991): “Les Phéniciens et l'Égypte”, [en] Atti del II Congresso Internazionale di Studi Fenici e Punici, Roma, vol. I, 7-17.

Lemos, I. S.

(2000): "Songs for Heroes. The Lack of Images in Early Greece", [en] N. K. Rutter - B. A. Sparkes (eds.), Word and Image in Ancient Greece, Edinburgh.

(2002): The Protogeometric Aegean. The Archaeology of the Late Eleventh and Tenth Century $B C$, Oxford.

Lemos, I. S. - Hatcher, H. (1991): "Early Greek Vases in Cyprus: Euboean and Attic", OJA 10, 197-208.

LÉVÊQUE, P. (1984): “Astarté s'embarque pour Cythère”, [en] H. Walter (ed.), Hommages à Lucien Lerat, Paris, vol. II, 451-457.

Lipinski, E. (1995): Dieux et déeses de l'univers phénicien et punique, Leuven. 
Lipinski, E. (ED.), (1987): Phoenicia and the East Mediterranean in the First Millennium B.C. (Proceedings of the Conference held in Leuven from the 14th to the 16th of November 1985), Leuven.

Loraux, N. (1981): Les enfants d'Athènes, Paris.

MAIER, F. G.

(1975): "The Temple of Aphrodite at Old Paphos", RDAC, 69-80.

(1979): "The Paphian Shrine of Aphrodite and Crete", [en] Karageorghis (ed.), 1979, 228234.

(1986): “Kinyras and Agapenor”, [en] Karageorghis (ed.), 1986, 311-318.

Maier, F. G. - Karageorghis, V. (1984): Paphos. History and Archaeology, Nicosia.

Malkin, I. (1994): Myth and Territory in the Spartan Mediterranean, Cambridge.

MARChetTi, P.

(1993): "Recherches sur les mythes et la topographie d'Argos. I. Hermes et Aphrodite", BCH 117, 211-223.

(1994): "Recherches sur les mythes et la topographie d'Argos", BCH 118, 131-160.

Marinatos, N. (2000): The Goddess and the Warrior. The Naked Goddess and Mistress of Animals in Early Greek Religion, London-New York.

Markoe, G.

(1996): "The Emergence of Orientalizing in Greek Art: Some Observations on the Interchange between Greeks and Phoenicians in the Eighth and Seventh Centuries B. C.", BASOR 301, 47-67.

(1998): "The Phoenicians on Crete: Transit Trade and the Search for Ores", [en] V. Karageorghis - N. Stampolidis (eds.), Eastern Mediterranean: Cyprus-Dodecanes-Crete 16th6th cent. B.C., Athens, 233-240.

Masson, O. (1961): Inscriptions chyporiotes Syllabiques, Paris.

Mazarakis Ainian, A. (1997): From Rulers'Dwelling to Temples. Architecture, Religion and Society in Early Iron Age Greece (1100-700B.C), (=Studies in Mediterranean Archeology $\mathrm{XXI})$, Jonsered.

Menadier, B. (2002): "The sanctuary of Hera Akraia and its Religious Connections with Corinth", [en] Hägg (ed.), 2002, 85-92.

Meritt, B. D. (1931): Corinth, VIII, I, Greek inscriptions, 1896-1927, Cambridge, Massachussets.

Michaelidou-Nicolau, I. (1987): "Repercussions of the Phoenician presence in Cyprus", [en] Lipinski (ed.), 1987, 331-338.

Moggi, M. (2005): "Marpessa detta Choira e Ares Gynaikothoinas", [en] E. Østby (ed.), Ancient Arcadia. Papers from the Third International Seminar on Ancient Arcadia, held at the Norwegian Institute at Athens, 7-10 May 2002, Athens, 139-150.

Morel, J.-P. (1984): "Présences et influences grecques en Italie centrale (VIIe-VIe siècles)", [en] J. Harmatta (ed.), Proceedings of the VIIth Congress of the Internatioal Federation of the Societies of Classical Studies, Budapest, 221-235.

Morgan, G.

(1978): “Aphrodite Cytherea", TAPA 198, 115-20. 
(1994): "The Evolution of the Sacral "Landscape": Isthmia, Perachora, and the Early Corinthian State", [en] S. E. Alcock - R. Osborne (eds), Placing the Gods. Sanctuaries and Sacred Space in Ancient Greece, Oxford, 105-142.

(2002): "The Corinthian Aristocracy and Corinthian Cult during the Eight Century BC", [en] Hägg (ed.), 2002, 45-51.

Morris, I. (2000): Archaeology as Cultural History, Oxford.

Morris, S. P. (1992): Daidalos and the Origin of Greek Art, Princeton.

Morris, S. P. - Papadopoulos, J. K. (1998): "Phoenicians and the Corinthian Pottery Industry”, [en] R. Rolle - K. Schmidt - R. F. Docter (eds.), Archäologische Studien in Kontaktzonen der antiken Welt, Göttingen, 251-264.

Musti, D. - Torelli, M.

(1986): Pausania. Guida della Grecia. Libro II. La Corintia e l'Argolide, Roma.

(1991): Pausania. Guida della Grecia. Libro III. La Laconia, Roma.

Näsström, B.-M. (1998): “Cybele and Aphrodite: Two aspects of the Great Goddess", [en] L. Larsson Lovén - A. Strömberg (eds.), Aspects of Women in Anquity, Jonsered, 29-43.

Nicolau, K. (1979): "Minoan survivals in Geometric and Archaic Cyprus", [en] Karageorghis (ed.), 1979, 249-256.

Novaro-Lefèvre, D. (2000): “Le culte d'Héra à Pérachora (VIIIe-Ve s.): essai de bilan”, REG $113,42-69$.

Oikonomides, A. L. (1964): The two Agoras in Ancient Athens, Chicago.

Olmo Lete, G. Del (ed.), (1995): Mitología y religión del Oriente Antiguo, II, 2. Semitas Occidentales, Barcelona.

OsAnNA, M.

(1988-1989): "Il problema topografico del santuario di Afrodita Urania ad Atene", ASAA 66-67, 73-95.

(1990): "Sui culti arcaici di Sparta e Taranto. Afrodite Basilis", PP 45, 81-94.

OstBy, E. ET ALII (1994): "The Sanctuary of Athena Alea at Tegea: First Preliminary Report (1990-1992)", OAth 20, 89-141.

Pala, E. (2010): “Aphrodite on the Acrópolis: Evidence from Attic pottery”, [en] Smith Pickup (eds.), 2010, 195-216.

Payne, H. ET ALII (1940): Perachora. The sanctuaries of Hera Akraia and Limenia, Oxford.

Pelagatti, P. (1964): "Naxos-Relazione Preliminare delle Campagne di Scavo 1961-1964", Bollettino d'Arte 49, 149-165.

Perlman, P. (2000): “Gortyn. The First Seven Hundred Years (Part I)”, [en] P. Flensted-Jenses et alii (eds.), Polis \& Politics. Studies in Ancient Greek History presented to M. H. Hansen on his Sixtieth Birthday, August, 20, Copenhagen, 59-89.

Piérart, M. - Touchais, G. (1996): Argos. Une ville grecque de 6000 ans, Paris.

Pirenne-Delforge, V.

(1987): “Aspects orientaux du culte d'Aphrodite à Athènes", [en] Lipinski (ed.), 1987, $145-156$.

(1994): L'Aphrodite grecque. Contribution à une étude de ses cultes et de sa personnalité dans le panthéon archaïque et classique (=Kernos suppl. 4), Liège.

(2001): "La genèse de l'Aphrodite grecque: le "dossier crétois", [en] Ribichini et alii (eds.), 2001, 169-187. 
Pirenne-Delforge, V. - Bonnet, C. (1999): "Deux déesses en interaction: Astarté et Aphrodite dans le monde égéen", [en] Les syncrétismes religieux dans le monde méditerranéen en l'honneur de F. Cumont (Rome, 25-27 Septembre, 1997), Turnhout, 249-273.

POPHAM, M. R.

(1981-82): "Why Euboea?, in Grecia, Italia e Sicilia nell'VIII e VII secolo a.C.”, ASAA 43-44, 237-239.

(1994): "Precolonization: Early Greek Contact with the East", [en] G. R. Tsetskhladze F. de Angelis (eds.), The Archaeology of Greek Colonisation. Essays Dedicated to Sir J. Boardman, Oxford, 11-34.

Popham, M. R. ET ALII (1980): Lefkandi I. The Iron Age, London.

PoradA, E. (1965): "Cylinder Seals from Thebes: A preliminary Report”, AJA 69, 173.

Pugliese Carrateli, G. (1990): Tra Cadmo e Orfeo. Contributi alla storia civile e religiosa dei Greci d'Occidente, Bologna.

REICHERT-SÜDBECK, P. (2000): Kulte von Korinth und Syrakus. Vergleich zwischen einer Metropolis und ihrer Apoikia, Würzburb.

Reyes, A. T. (1994): Archaic Cyprus. A Study of the Textual and Archaeological Evidence, Oxford.

Ribichini, S. (2004): “Al servizio di Astarte. Ierodulia e prostituzione sacra nei culti fenici e punici”, [en] A. González Blanco - G. Matilla-A. Egea (eds.), El mundo púnico. Religión, Antropología y cultura material (=Estudios Orientales 5-6), Murcia, 55-68.

RiBICHINI, S. ET ALII (EDS.), (2001): La Questione delle influenze vicino-orientali sulla religione greca, Roma.

Rocchi, M. (1994): “Ares Aphneios-Aeropos-Echemos”, RCCM 36, 69-78.

Rosenzweig, R. (1999): Aphrodite in Athens: a study of art and cult in the Classical and late Classical periods, University of Oregon, $\mathrm{Ph}$. D. Thesis.

RudHARDT, J. (1975): "Quelques notes sur les cultes chypriotes, en particulier sur celui d'Aphrodite", [en] Chypre des origines au moyen age (Séminaire interdisciplinaire Semestre d'été 1975, Univ. de Genève), Genève, 109-154.

Scandone Matthiae, G. (1991): "Hathor Signora di Biblo e la Baalat Gebal", [en] E. Acquaro et alii. (eds.), Atti del II Congresso Internazionale di Studi Fenici e Punici (Roma, 9-14 Novembre 1987), Roma, vol. I, 401-406.

SCHACHTER, A.

(1981): Cults of Boiotia, London, vol. I.

(1985): "Kadmos and the Implications of the Tradition for Boiotian History", [en] La Béotie Antique (Lyon-Saint-Étienne, mai 1983), Paris, 145-153.

Schindler, R. (1998): The Archaeology of Aphrodite in the West, University of Michigan, Ph. D. Thesis.

SenfF, R. (2003): “Das Aphroditeheiligtum von Milet”, AMS 49, 11-25.

Servais-Soyez, B. (1983): “Aphrodite Ouranie et le symbolisme de l'échelle. Un message venu d'Orient", [en] H. Limet - J. Ries (eds.), Le Mythe son language et son message (Actes du Colloque de Liège et Louvain-La-Neuve, 1981), Louvain-La-Neuve, 189-207.

SERwint, N. (2002): “Aphrodite and her Near Eastern Sisters: Spheres of Influence”, [en] D. Bolger - N. Serwint (eds.), Engendering Aphrodite: Women and Society in Ancient Cyprus, American Schools of Oriental Research, Boston, 325-350. 
Settis, S. (1966): XELONE. Saggio sull'Afrodite Urania di Fidia, Pisa.

SHAw, J. W. (1989): "Phoenicians in Southern Crete", AJA 93, 165-183.

Simon, E. (1970): “Aphrodite Pandemos auf Attischen Münzen”, SNR, 5-19.

Smith, A. C. - Pickup, S. (eds.), (2010): Brill's companion to Aphrodite, Leiden-Boston.

Smithson, E. L. (1968): “The Tomb of a Rich Athenian Lady ca. 850 B.C.", Hesperia 37, 77-116.

SNOdGrass, A. M.

(1971): The Dark Age of Greece, Oxford, 1971.

(1986): "The Historical Significance of Fortification in Archaic Greece", [en] P. Leriche H. Tréziny (eds.), La fortification dans l'histoire de monde grec, Paris, 126-131.

Strom, I. (1992): "Evidence from the Sanctuaries", [en] G. Kopcke - I. Tokumaru (eds.), Greece between East and West: 10th-8th Centuries BC (Papers of the Meeting at the Institute of Fine Arts, New York Univesity March 15-16th, 1990), Mainz, 46-60.

Tomlinson, R. A. (1972): Argos and the Argolid, Ithaca.

Torelli, M. (1977): "Il Santuario greco di Gravisca", PP 32, 398-458.

Ulbrich, A. (2010): "Images of Cypriot Aphrodite in her Sanctuaries During the Age of the City-Kingdoms”, [en] Smith - Pickup (eds.), 2010, 167-193.

VALDÉS, M.

(2002): "Los "espacios" de Afrodita en la polis arcaica de Atenas", ARYS 5, 4-32.

(2005): El papel de Afrodita en el alto arcaísmo: política, guerra, matrimonio e iniciación, Mesina.

(2005a): "The cult of Aglauros (and Aphrodite) in Athens and in Salamis of Cyprus: Reflections on the Origin of the Genos of the Salaminioi", Ancient West\&East 4/1, 57-76.

(e.p.): "Influencia oriental en la Afrodita griega (Urania): encuentros y desencuentros entre la cultura griega y la oriental", [en] IX Congreso de la SECR. Religiones en sociedades complejas: encuentros y desencuentros (Octubre de 2011).

Vandenabeele, F. (1986): "Phoenician Influence on the Cypro-Archaic Terracotta Production and Cypriot Influence Abroad”, [en] Karageorghis (ed.), 1986, 351-358.

VIAN, F. (1963): Les origines de Thèbes, Paris.

Villing, A. C. (1997): "Aspects of Athena in the Greek Polis: Sparta and Corinth", [en] A. B. Lloyd (ed.), What is a God? Studies in the Nature of Greek Divinity, London, 81-100.

Voyatzis, M. E.

(1985): "Arcadia and Cyprus: Aspects of their Interrelationship between the Twelfth and Eighth Centuries B.C.", RDAC, 158-162.

(1999): "The Role of Temple Building in Consolidating Arkadian Communities", [en] T. H. Nielsen - J. Roy (eds.), Defining Ancient Arkadia (=Acts of the Copenhagen Polis Centre 6), Copenhagen, 130-168.

(2002): “An Analysis of Votive Types Recently Found at Tegea”, [en] Hägg (ed.), 2002, 159-169.

Walter, H. (1959): “Korinthische Keramik”, $\operatorname{MDAI}(A)$ 74, 57-68.

West, M. L.

(1988): “The Rise of the Greek Epic", JHS 108, 151-172.

(1997): The East Face of Helicon, Oxford. 
Williams II, CH. K.

(1978): Pre-roman Cults in the Area of the Forum of Ancient Corinth, Pennsylvania.

(1986): "Corinth and the Cult of Aphrodite", [en] M. Del Chiaro (ed.), Studies in Honor of Darrel A. Amyx, Columbia, 12-24.

Woodward, A. M. (1928-29): "Sparta. Votive Inscriptions from the Acropolis", ABSA 30, 241-254.

Yon, M. (1987): “Le royaume de Kition. Époque archaïque”, [en] Lipinski (ed.), 1987, $357-$ 374.

ZusAneck, H. (1994): Rhodos und Helios, Frankfurt-Main-Berlin-NewYork-Paris-Wien. 